\title{
Strategic Plan for the U.S. Geological Survey Status and Trends of Biological Resources Program: 2004-2009
}

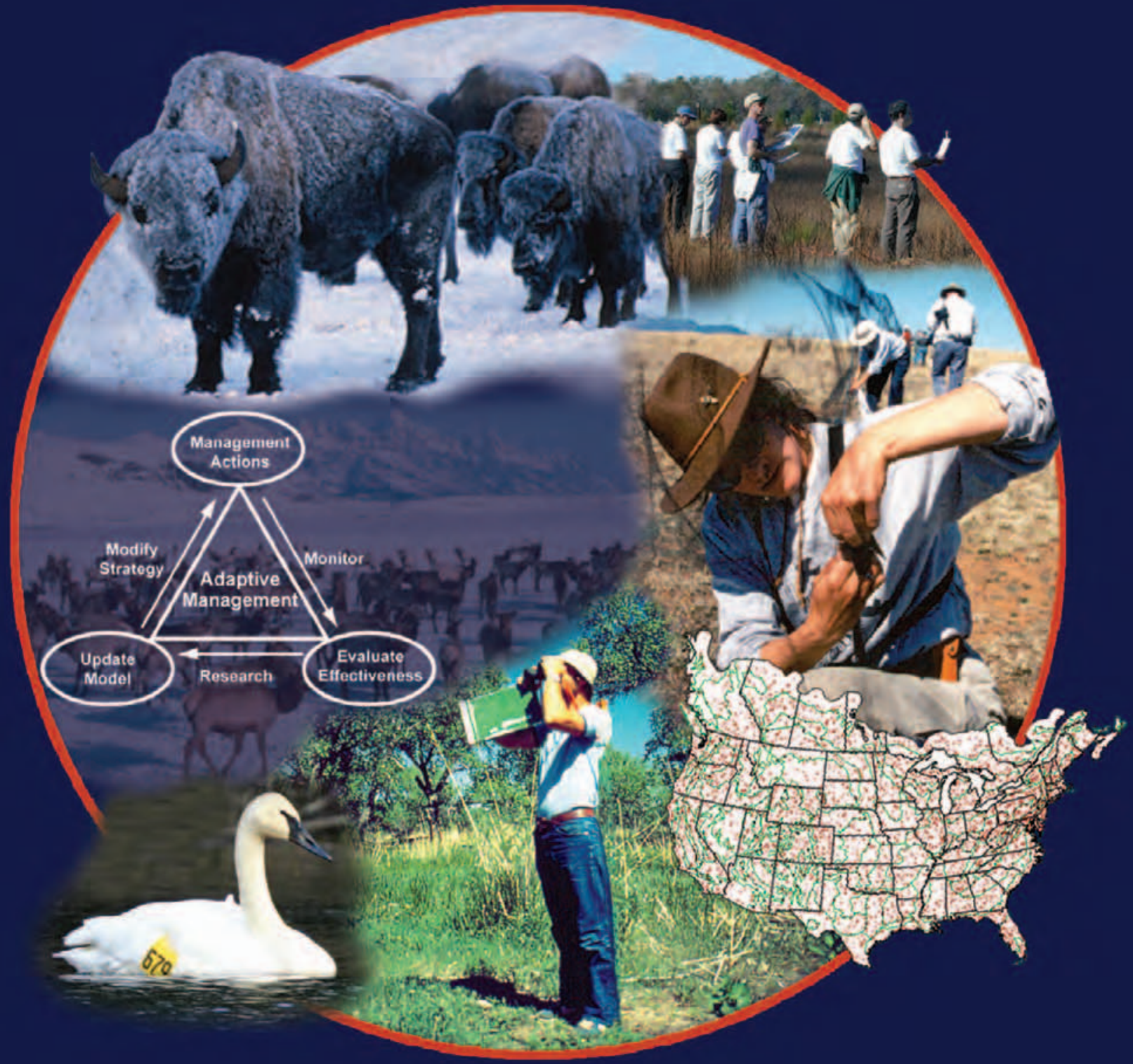

Circular 1277 


\section{In Memoriam}

In memory of Timothy M. Bartish (1956-2004), who, as leader of the Biomonitoring of Environmental Status and Trends (BEST) Program, made significant contributions to ecological monitoring on a national scale, to the development of this Plan, and most importantly, to the lives of his family and many colleagues and friends. 


\section{Strategic Plan for the U.S. Geological Survey Status and Trends of Biological Resources Program: 2004-2009}

By Paul V. Dresler, Daniel L. James, Paul H. Geissler, Timothy M. Bartish, and James Coyle

Circular 1277

U.S. Department of the Interior

U.S. Geological Survey 


\section{U.S. Department of the Interior \\ Gale A. Norton, Secretary \\ U.S. Geological Survey \\ Charles G. Groat, Director}

\section{U.S. Geological Survey, Reston, Virginia: 2004}

For more information about the USGS and its products:

Telephone: 1-888-ASK-USGS

World Wide Web: http://www.usgs.gov/

Any use of trade, product, or firm names in this publication is for descriptive purposes only and does not imply endorsement by the U.S. Government.

Although this report is in the public domain, it contains copyrighted materials that are noted in the text. Permission to reproduce those items must be secured from the individual copyright owners.

Suggested citation:

Dresler, P.V., James, D.L., Geissler, P.H., Bartish, T.M., and Coyle, J., 2004, Strategic Plan for the U.S. Geological Survey Status and Trends of Biological Resources Program: 2004-2009: U.S. Geological Survey, Biological Resources Discipline, Circular 1277, 23 p. 


\section{Contents}

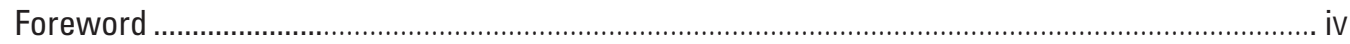

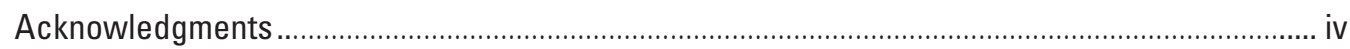

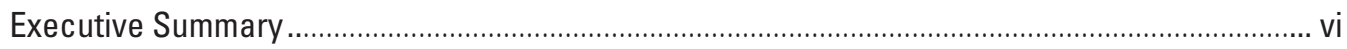

Why Monitor the Status and Trends of Biological Resources? ................................................... 1

What Is the Organizational Context and Role of the Program? .................................................... 1

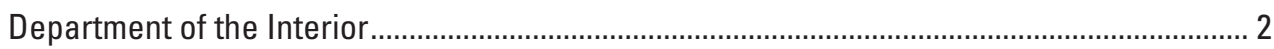

U.S. Geological Survey ................................................................................................. 2

USGS Status and Trends of Biological Resources Program .................................................. 3

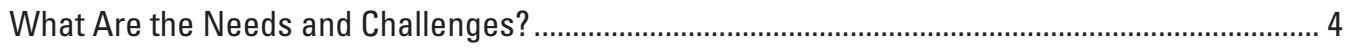

Greater Integration of Data and Information at Multiple Scales.............................................. 4

A Systems Perspective of Status and Trends ..................................................................... 4

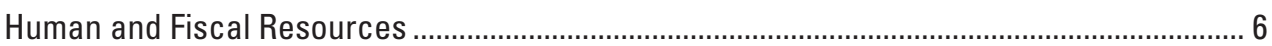

Where Are We Going?. 6

A National Framework for Monitoring Biological Resources .................................................... 6

How Will We Get There? ................................................................................................................ 7

Goal 1: Develop a Conceptual Model and the Required Infrastructure (a National Monitor-

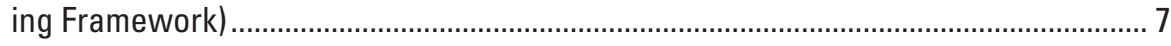

Goal 2: Develop and Evaluate Inventory and Monitoring Methods........................................ 9

Goal 3: Collect, Manage, Archive, and Share Critical, High-Quality Monitoring Data ............. 9

Goal 4: Produce and Provide Analyses and Reports that Synthesize Information ................. 10

Implementation ............ 10

Table 1. Strategic Plan Goals, Objectives, Strategies, Outcomes, and Measures for Achieving the Mission of the Status and Trends of Biological Resources Program, 2004-2009........ 11

Figure 1. Summary and Timeline of Status and Trends Program Goals, Objectives, Outcomes, Measures, and Milestones: 2004-2009......................................................................... 19

Table 2. Recommended Directions by Taxa and Theme for Advancing Program Goals................. 20

List of Abbreviations...

References Cited ........ 23 


\section{Foreword}

The Status and Trends of Biological Resources Program of the U.S. Geological Survey (USGS), Biological Resources Discipline (BRD), established a Program Planning Committee to develop a 5-year Strategic Plan. The Committee was selected from nominees recommended by USGS-BRD Science Center Directors and included representatives from the Water Resources, Geology, and Geography Disciplines. Committee members represent a wide range of regional, interdisciplinary, and intra-bureau scientific and technical perspectives.

The Committee was encouraged to solicit input from peers within and outside of the USGS, including other Department of the Interior (DOI) bureaus, other federal and state agencies, and non-governmental organizations. This dialog with internal and external clients and partners ensured a lively debate concerning the challenges of and approaches to meeting Program goals. Committee members were also tasked with summarizing the goals, objectives, deliverables, and measures of success for selected ongoing Program activities. The resulting "topical papers" provided the basis for discussions that led to the Program priorities addressed in this Strategic Plan.

The Plan describes a vision for assessing the status and trends of the Nation's biological resources and sets milestones for measuring progress over the next 5 years. It presents a strategy for moving the Program beyond a "large collection of projects" (USGS, 1999) toward an integrated and focused effort to address identified monitoring information needs. A critical aspect of this Plan is the development of a National Monitoring Framework for biological resources. The Framework is intended to provide a structure for achieving better data sharing and integration related to biological monitoring.

This Plan also envisions long-term participation and involvement by the full community, public and private, that may collect and/or use biological resource monitoring data and information. It addresses requirements of the Office of Management and Budget (OMB) Program Assessment Rating Tool (PART), and meets the planning process requirements outlined by the USGS Director. Just as important, the Plan provides for accountability of the Program to the USGS, DOI, OMB, Congress, and the public.

Recognizing that input from stakeholders is critical to Plan success, the Program solicited review and comment on the Plan from individuals representing a variety of federal, state, tribal, and non-governmental organizations. Their thoughts and comments were integral to creating a plan relevant to resource management needs.

\section{Acknowledgments}

The efforts, dedication, and input of our many colleagues in the USGS and partner/client agencies and organizations clarified our vision and refined and enriched the Status and Trends of Biological Resources Program Strategic Plan. To begin with, we would not have a Plan were it not for the initial labors, expertise, and vision of the Planning Committee. The team comprised:

Steve Amstrup, Alaska Science Center

Tim Bartish, Status and Trends of Biological Resources Program, BEST Program

Jayne Belnap, Southwest Biological Science Center

Rob Bennetts, Florida Integrated Science Center

David Busch, Forest and Rangeland Ecosystem Science Center

Steve Corn, Northern Rocky Mountain Science Center

Paul Dresler, Status and Trends of Biological Resources Program Coordinator

George Durner, Alaska Science Center 
Paul Geissler, Status and Trends of Biological Resources Program, National

Park Monitoring

Tom Gunther, Geographic Information Office

Pam Haverland, Columbia Environmental Research Center

Marshall Howe, Patuxent Wildlife Research Center

Dan James, Status and Trends of Biological Resources Program

Barry Johnson, Upper Midwest Environmental Sciences Center

Doug Johnson, Northern Prairie Wildlife Research Center

Jimmy Johnston, National Wetlands Research Center

Tim King, Leetown Science Center

Lee Lamb, Fort Collins Science Center

Tom Loveland, Geography Discipline, EROS Data Center

Steve Moulton, Water Resources Discipline, National Water Quality Assessment

Karen Oakley, Alaska Science Center

Dave Pyke, Forest and Rangeland Ecosystem Science Center

Mike Ruggiero, Biological Information Management Program, Taxonomic Information

John Sauer, Patuxent Wildlife Research Center

Chris Schmitt, Columbia Environmental Research Center

Steve Schwarzbach, Western Ecological Research Center

Bern Shanks, Western Regional Office

Tom Stohlgren, Fort Collins Science Center

David Woodson, Western Regional Office

Lisa Zolly, Biological Information Management Program

Our cadre of reviewers provided invaluable suggestions and insights to make the Plan more reflective of land and resource manager needs. We especially thank the reviewers from the U.S. Department of Agriculture Forest Service, Bureau of Land Management, and U.S.

Fish and Wildlife Service, as well as The Ornithological Council, International Association of Fish and Wildlife Agencies, and many of our colleagues at USGS Science Centers across the country for their significant contributions to the quality of this Plan.

Special thanks go to Carolyn Bell, USGS Communications Officer, who served as facilitator for the Planning Committee meetings, and to Tony Frank, USGS Eastern Regional Office, and Mike Ruggiero, who persevered in advancing the draft Plan through its later stages.

Finally, we acknowledge Melissa Dresler, who reviewed and edited the many iterations; Juliette Wilson of Johnson Controls World Services (under contract to the USGS Fort Collins Science Center), who incorporated review comments and conducted the final edits; and Jennifer Shoemaker and Dora Medellin at the Fort Collins Science Center, who designed and generated the final publication. 


\section{Executive Summary}

The mission of the USGS Status and Trends of Biological Resources Program is to measure, predict, assess, and report the status and trends of the Nation's biological resources to facilitate research, enable resource management and stewardship, and promote public understanding and appreciation of our living resources. Determining the status (abundance, distribution, productivity, and health) and trends (how these variables change over time) of our living natural resources is critical for their protection or restoration. The Program provides the USGS, other agencies of the Department of the Interior (DOI), other federal and state agencies, and the

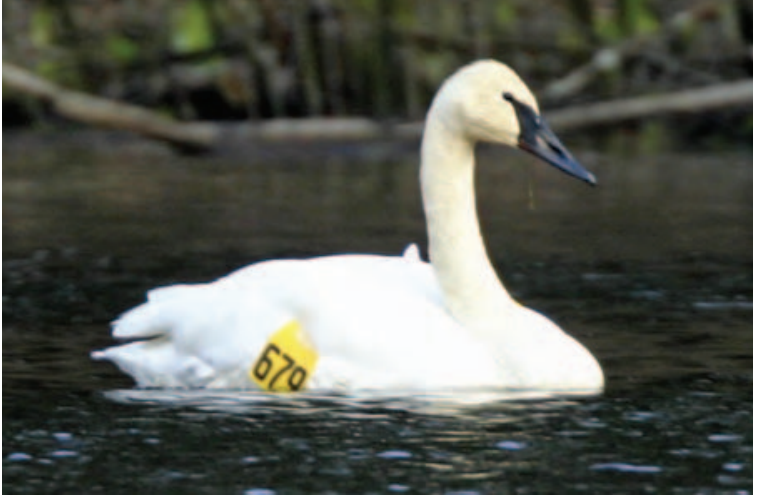

Trumpeter swan with numbered wing tags. This technique allows birds to be monitored remotely without the need for recapture to identify individuals. Photo by Wayne Miller. public with science-based monitoring data and information for local, regional, and national assessment of biological resources and the ecosystems that support them.

The Status and Trends Program developed this Strategic Plan to better meet the biological inventory and monitoring information needs of the land and resource management community. By setting clear goals, strategies, and measures of success, this Plan will guide development of a more cohesive, unified Program over the next 5 years. Further, the Plan outlines strategies for increasing communication, cooperation, and collaboration among the USGS and other agencies and organizations involved in biological resource monitoring. Most importantly, the Plan envisions a process where scientifically valid biological status and trends information, across multiple spatial and temporal scales, is readily available to land and resource managers and their stakeholders to inform and enable sound stewardship of the Nation's biological resources and their supporting ecosystems.

Over the next 5 years, progress made in addressing each long-term Program goal and its associated 5-year priority objectives will gauge the Plan's success. Specific strategies, outcomes, and measures of success related to accomplishing these goals and objectives, both programmatically and within the context of specific taxa, are described in this Plan and are summarized in Tables 1 and 2 and Figure 1.

All of the following goals involve partnering to coordinate and integrate information collection, management, and dissemination. Such cooperation and collaboration, built purposefully and steadily over time, is essential to their achievement.

\section{Goal 1: Develop a Conceptual Model and the Required Infrastructure (A National Monitoring Framework) that Facilitates the Integration of Information from a Variety of Sources, at Multiple Spatial and Temporal Scales, to Describe and Track the Abundance, Distribution, Productivity, and Health of the Nation's Plants, Animals, and Ecosystems}

The Program will work to develop a conceptual model and the required partnerships (a National Monitoring Framework) to facilitate the acquisition, sharing, and integration of scientifically valid status and trends information. In partnership with collaborators, a document will be developed describing the elements that constitute the Framework, the organizational relationships among them, and their contribution to the accomplishment of existing and emerg- 
ing biological resource monitoring goals. The Framework will undergo periodic review and refinement, and will foster improved programmatic efficiencies and economies of scale through better collaboration than currently exists among public and private organizations.

\section{Goal 2: Develop and Evaluate Inventory and Monitoring Methods, Proto-} cols, Experimental Designs, Analytic Tools, Models, and Technologies to Measure Biological Status and Trends

Achievement of a holistic approach to monitoring the status and trends of biological resources will require that methodologies are current, appropriate to their intended purpose, well documented, scientifically sound, and to the extent possible, compatible among studies. As a part of this effort, the Program will network and cooperate with DOI and other public and private organizations conducting research programs that involve developing biological inventory and monitoring tools and techniques.

\section{Goal 3: Collect, Manage, Archive, and Share Critical, High-Quality Moni- toring Data in Cooperation with Partners to Enable a Determination of the Status and Trends of Biological Resources}

At the heart of the Program are its existing monitoring activities, and the USGS is committed to continuing the data collection activities that are core to its mission (USGS, 2002). Here again, the Program will coordinate with other agencies and organizations engaged in biological inventory and monitoring to harmonize monitoring efforts and identify gaps where further investments are warranted.

\section{Goal 4: Produce and Provide Analyses and Reports that Synthesize Infor- mation on the Status and Trends of Our Nation's Flora, Fauna, and Eco- systems and Respond to the Needs of the Scientific Community, Land and Resource Managers, Policymakers, and the Public}

The Program will assess the information collected and produce reports that are relevant to resource management and biological research needs, and provide information and technical support that also meet the needs of DOI and other resource management agencies. 



\section{Strategic Plan for the U.S. Geological Survey Status and Trends of Biological Resources Program: 2004-2009}

\section{Why Monitor the Status and Trends of Biological Resources?}

The Nation's living resources and the habitats on which they depend are undergoing constant change. In the face of influences like climate change, invasive species, and a plethora of human activities, natural resource management and conservation efforts are becoming increasingly challenging and complex.

To protect and conserve the living resources entrusted to their care, land and resource managers must first understand the condition, or status, of those resources:

- inventory (what they are),

- abundance (how many there are),

- distribution (where they are located),

- productivity (their capacity to reproduce), and

- health (their well-being, resilience);

and their trends (how these variables change over time and space).

Credible, long-term monitoring is required to satisfy these information needs. In addition, long-term monitoring can be used for

- detecting changes that may signal degradation of or improvement in natural systems,

- identifying new or emerging conditions that signal the need for management action or further investigative research,

- providing feedback critical to evaluating the effectiveness of specific management actions in adaptive management (see inset),

- validating research results and models, and

- promoting increased public understanding and appreciation of the status and trends of our living resources.

\section{What Is the Organizational Context and Role of the Program?}

The U.S. Geological Survey (USGS) Status and Trends of Biological Resources Program recognizes that a wide variety of public and private organizations are involved in biological or ecological monitoring efforts. Examples include federal entities such as the Departments of the Interior (DOI), Agriculture (USDA), Commerce, Defense, Energy, and Transportation; the Environmental Protection Agency; the National Science Foundation; and the National Aeronautics and Space Administration (NASA) — as well as tribal and state governments, academic and research institutions, and nongovernmental organizations (NGOs). This Plan acknowledges the value of these ongoing efforts and promotes collaboration in sharing and integrating data and information generated by the diverse monitoring community. Enhanced cooperation will expand our ability to understand and forecast the condition of our shared biological resources.

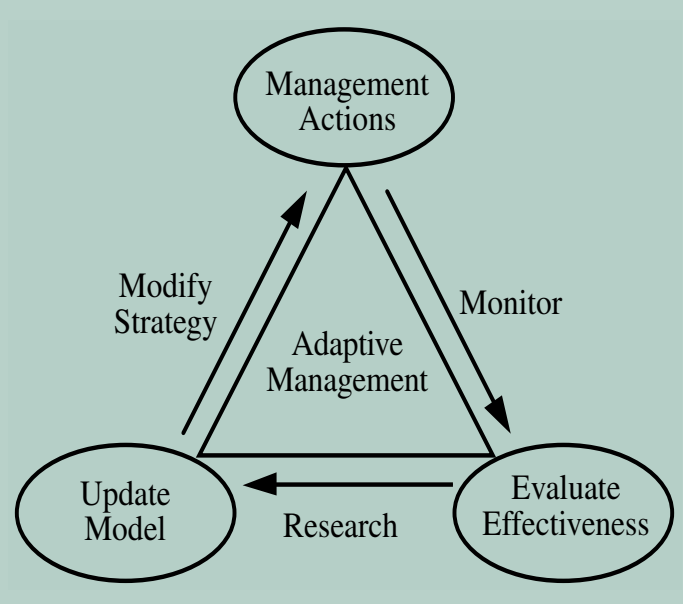

Adaptive resource management is a sequential decision-making process for continually improving management policies and practices by learning from the outcomes of previous decisions (Walters, 1986). Long-term monitoring at regular intervals is a critical component of this process to evaluate the resource's response to management action and detect change that may require either adjustments in management actions or further investigative research. In addition, long-term monitoring can span changes driven by natural forces, such as unusual weather patterns, disease events, fire, changes in predator densities, or other factors, so the managers can recognize trends, anticipate outcomes, and adapt management actions to respond to them. 
The remainder of this section places the Plan within the context of the DOI and USGS strategic plans and explains how this Plan addresses and responds to their respective monitoring requirements.

\section{Department of the Interior}

The mission of the DOI is to protect and manage the Nation's natural resources and cultural heritage; provide scientific and other information about those resources; and honor its trust responsibilities or special commitments to American Indians, Alaska Natives, and affiliated Island Communities. To meet its stewardship responsibilities, as conveyed by numerous legislative authorities, ${ }^{1}$ the DOI is mandated to estimate the availability and abundance of fish and wildlife resources, determine the distribution and abundance of migratory birds, investigate and report on North American birds, conduct inventories of all public lands and their resources, implement programs for endangered and threatened wildlife and plants, conserve marine mammals, and implement the Convention on Great Lakes Fisheries.

The Department relies upon biological monitoring information to achieve its mission, measure its success in responding to these legislative mandates, and determine its progress toward meeting DOI Resource Protection goals. These include:

- improving the health of watersheds, landscapes, and marine resources that are DOI-managed or influenced in a manner consistent with obligations regarding the allocation and use of water;

- sustaining biological communities on DOI-managed and influenced lands and waters in a manner consistent with obligations regarding the allocation and use of water; and

- protecting cultural and natural heritage resources.

"Now and in the future, rigorous approaches to inventorying and monitoring wildlife resources are needed to provide the information critical to devise, evaluate, and refine management strategies implemented to meet refuge goals and objectives."

U.S. Fish and Wildlife Service (1999) goals (see box, page 3). More specifically, the DOI Plan identifies performance measures for evaluating its success in

${ }^{1}$ For example, the Antiquities Act, National Park Service Organic Act, Lacey Act, Endangered Species Act, National Wildlife Refuge System Administration Act, and Federal Land Policy and Management Act.
"A major part of protecting those resources is knowing what they are, where they are, how they interact with their environment and what condition they are in. This involves a serious commitment from the leadership of the National Park Service to insist that the superintendents carry out a systematic, consistent, professional inventory and monitoring program, along with other scientific activities, that is regularly updated to ensure that the Service makes sound resource decisions based on sound scientific data."

U.S. House of Representatives (1999)

achieving desired habitat conditions, restoring burned areas, establishing sustainable populations of targeted species, and evaluating the status and trends of invasive species. The availability of scientifically credible monitoring information is crucial to the ability of DOI to achieve its resource management objectives as demonstrated through established performance measures. Many of the priorities in the Status and Trends Program Strategic Plan derive from and directly support stated DOI information needs. Relationships between DOI goals and Program strategies and desired outcomes are cross-referenced in Table 1.

\section{U.S. Geological Survey}

The USGS is the DOI's principal science agency. As such, it is entrusted to provide unbiased, independent data and information on hydrology, geology, geography, and biology. ${ }^{2}$ Specifically, the USGS serves the Nation by providing reliable scientific information to describe and understand the Earth; minimize loss of life and property from natural disasters; manage water, biological, energy, and mineral resources; and enhance and protect our quality of life. Included in the USGS mission are requirements to collect natural resource information and conduct systematic analyses and investigations to inform natural resource decision making (USGS, 2002). To achieve its mission, the USGS intends to "continue to improve the quality and usefulness of its long-term data sets," and, where appropriate, work with partners (other federal, state, tribal, and local governments; academic and research institutions; and private organizations) to acquire the necessary data.

\footnotetext{
${ }^{2}$ The Organic Act, 43 U.S.C. 31 et seq., 1879; Fish and Wildlife Coordination Act, 1934; Fish and Wildlife Act, 1956; Migratory Bird Treaty Act, 1918; Migratory Bird Conservation Act, 1900; Federal Land Policy and Management Act, 1976; Fish and Wildlife Improvement Act, 1978; Endangered Species Act, 1973; Marine Mammal Protection Act, 1972; Great Lakes Fishery Act, 1956; Nonindigenous Aquatic Nuisance Prevention and Control Act, 1990; Water Resources Development Act, 1990; and other authorizations conveyed to the U.S. Geological Survey.
} 


\section{Department of the Interior Strategic Plan \\ Goals and Strategies*}

End Outcome Goal 1. Improve the health of watersheds, landscapes, and marine resources that are DOI-managed or influenced in a manner consistent with obligations regarding the allocation and use of water.

Strategy 1-1: Restore and maintain proper function to watersheds and landscapes.

Strategy 1-2: Improve information base, information management, and technical assistance.

End Outcome Goal 2. Sustain biological communities on DOI-managed and influenced lands and waters in a manner consistent with obligations regarding allocation and use of water.

Strategy 2-1: Create habitat conditions for biological communities to flourish.

Strategy 2-2: Manage populations to self-sustaining levels for specific species.

Strategy 2-3: Improve information base, information management, and technical assistance.

End Outcome Goal 3. Protect cultural and natural heritage resources.

Strategy 3-1: Increase knowledge base of cultural and natural heritage resources managed or influenced by DOI.

Strategy 3-2: Manage Special Management Areas for natural heritage resource objectives.

Strategy 3-3: Reduce degradation and protect cultural and natural heritage resources.

Strategy 3-4: Increase partnerships, volunteer opportunities, and stakeholder satisfaction.

*DOI, 2003. DOI and Status and Trends Program goals and strategies coincide and/or support one another. Monitoring underpins the associated measures and outcomes. For a detailed analysis and specific linkages, refer to Table 1, p. 11.

\section{USGS Status and Trends of Biological Resources Program}

The Program responds to the monitoring and information needs and requirements of both the DOI and the USGS. It works closely with the resource management community to provide scientifically sound approaches to fulfilling its mission of measuring, predicting, assessing, and reporting the status and trends of our living resources. This Strategic Plan defines the Program goals and outlines a strategy for achieving this mission. The Plan also serves as a tool to guide Program management through periodic Program reviews, annual project reviews, and day-to-day operations.

Program Activities. The Program currently comprises a wide variety of activities. The major components of this approximately \$19 million Program are projects focused on national park monitoring; bird, mammal, and fish monitoring; vegetation mapping; contaminant effects monitoring; development of monitoring standards and protocols; taxonomy, statistics, and museum studies; predictive population modeling; science for decision support systems; adaptive management; and human dimensions and socioeconomics. Program work is enhanced by many additional monitoring projects funded through other internal and external programs and partners.

In FY 2004, there were more than 250 activities funded by the Program. These projects, tasks, and subtasks address

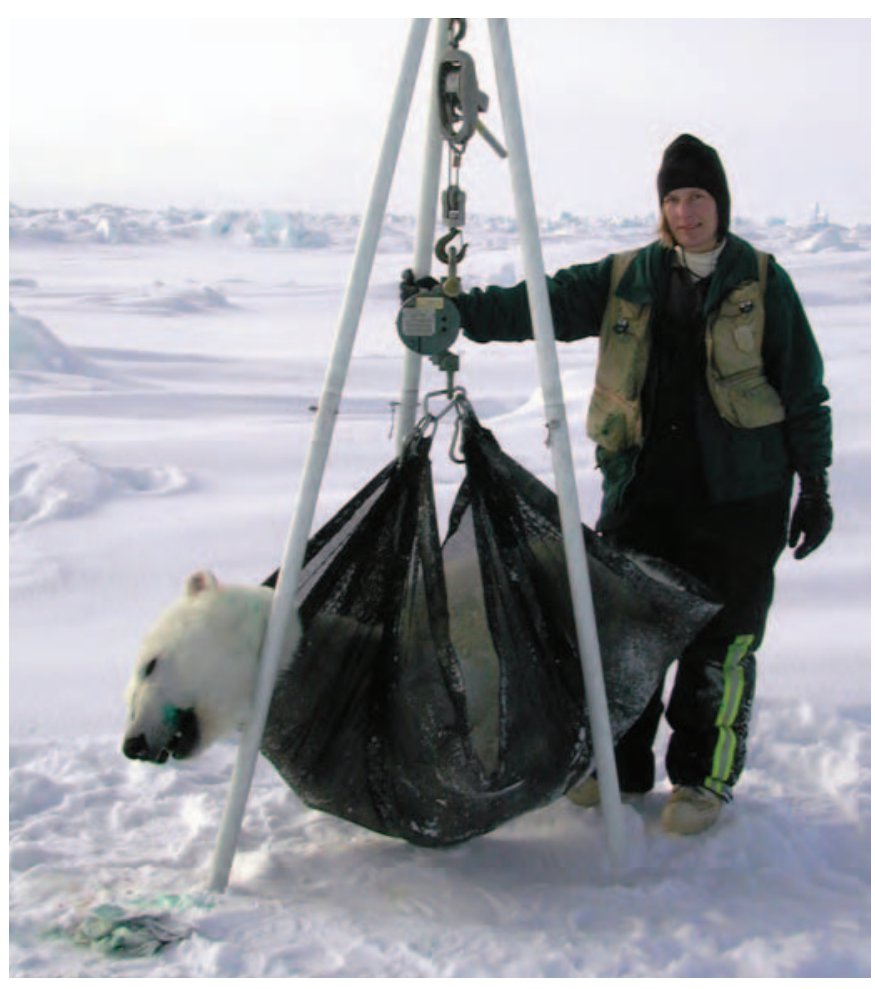

Kristin Simac of the Alaska Science Center's Polar Bear Research Project weighs a radio-collared bear captured on the pack-ice of the Alaskan Beaufort Sea. Photo by Steven Amstrup, USGS. 


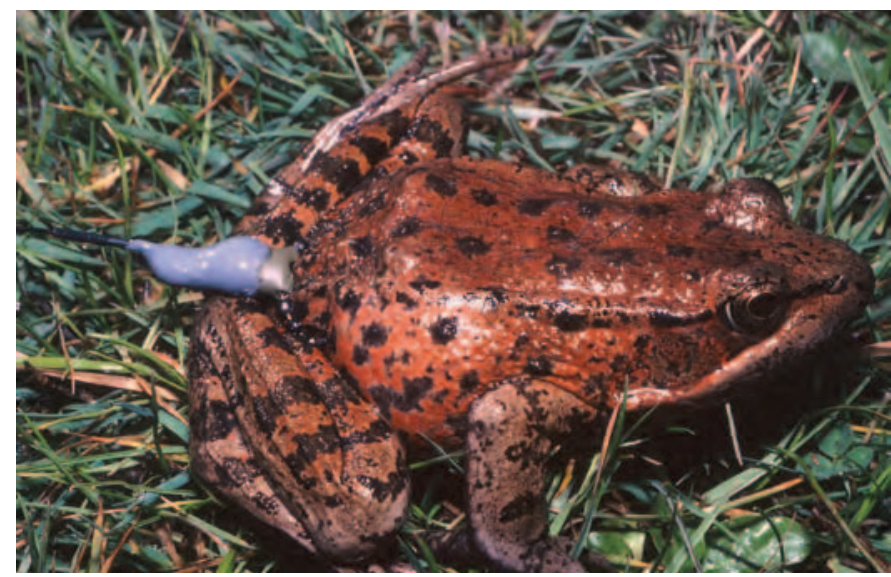

This endangered California red-legged frog wears a belt-attached transmitter that allows scientists to track individual movements. Photo by Gary M. Fellers, USGS.

status and trends of the full range of biological resources, from wildlife disease pathogens to marine mammals in the Arctic. They also include trends related to socioeconomic factors that influence visitation to public lands. Program activities are diverse given their origins in various DOI bureaus with different missions and priorities. For example, the Program includes (1) status and trends monitoring for endangered species, migratory birds, and marine mammals to help the U.S. Fish and Wildlife Service meet its requirements to manage and protect public trust resources; (2) Great Lakes fish stock assessments to satisfy international agreements and Native American treaty obligations; (3) monitoring of select biota within networks of national parks to help preserve their natural resources and promote biodiversity; and (4) inventory and monitoring of vegetation, invertebrates, and fish populations to assess the impacts of human activities in the Upper Mississippi River for the U.S. Army Corps of Engineers.

Through projects like these and similar efforts (see box, page 5), the Program continues to successfully produce data and information that is highly relevant and timely. A formal review of the Program (USGS, 1999) found that "the Status and Trends Program is a strong and valuable part of the BRD [Biological Resources Discipline] and that...BRD has established strong scientific expertise and leadership in many aspects of inventory and monitoring."

\section{What Are the Needs and Challenges?}

\section{Greater Integration of Data and Information at Multiple Scales}

Although individual projects of the Program are providing valuable information to the USGS and its partners, they have not yet been integrated into a comprehensive strategy for holistically assessing the abundance, distribution, productivity, and health of the Nation's plants, animals, and ecosystems. Because they originated in other DOI bureaus with different missions and/or legislative mandates, these monitoring activities are not always comparable or compatible in their design, methodology, or purpose. Further, they are not fully complementary: collectively, they do not represent a complete and comprehensive program of status and trends services and expertise.

The synthesis of data and information derived from biological monitoring projects is a key need. This will produce a more complete, holistic understanding of the status and trends of living systems, spanning multiple spatial and temporal scales. The Program Review (USGS, 1999) stated that "BRD scientists need to view themselves as vital elements of an overall Status and Trends research team that collectively contribute to a grand vision." Hence, the Program needs to move beyond "a loose collection of projects" and integrate information across scales and from multiple sources. However, progress toward integration must be accomplished without compromising the ability to address the data and information needs associated with ongoing, site-specific USGS Status and Trends projects, even as we work to consolidate and align them into a cohesive whole.

The USGS must work with partners and clients to generate relevant biological monitoring data that forms the basis for sound resource management decisions. Only with their participation can a national framework of cooperation and partnership begin to emerge.

"The U.S. government spends hundreds of millions of dollars on the collection of natural resource and environmental data. These activities produce a wide variety of information, designed to be useful in the context of regulatory and management programs. Other entities likewise have used a variety of approaches and chosen different sets of indicators. These activities provide a good basis for further work. Currently the U.S. government does not have a framework to guide federal indicator development or provide a consistent analytic basis for working with international, state or non-governmental indicators endeavors."

CEQ (2002)

\section{A Systems Perspective of Status and Trends}

Just as important, the Program needs to approach the status and trends of biological resources from a systems perspective. This means focusing on a holistic view of all species and their habitats placed within a context of the systems (ecosystems) in which they reside. This systems approach to monitoring will require that knowledge be acquired at multiple biological (genetic, species, populations, 


\section{Examples of Recent Accomplishments and Ongoing Work of the USGS Status and Trends Program}

Breeding Bird Survey (BBS). The BBS is a long-term, continental avian monitoring project designed to track the status and trends of North American bird populations. Each year, during the height of the avian breeding season, participants skilled in avian identification collect bird population data from over 4,100 survey routes located across the continental U.S. and southern Canada. The data provide an index of population abundance that can be used to estimate population trends and relative abundances at various geographic scales. BBS data were instrumental in focusing research and management action on neotropical migrant species in the late 1980s and on grassland species in the mid-1990s. Over 270 scientific publications have drawn heavily from BBS data.

Monitoring Great Lakes Fisheries. Fisheries are a valuable natural resource in the Great Lakes Region, and coordinated research programs are needed to sustain the productivity of these important fish populations. State, tribal, and federal managers across the Great Lakes basin have requested help in providing accurate assessments of fluctuating prey fish populations. For over 30 years, the Great Lakes Science Center has conducted annual bottom trawl surveys in all five Great Lakes that focus on the health of prey fish populations such as alewife, rainbow smelt, bloater, sculpin, and lake herring. This information helps managers with decisions concerning top fish predators (e.g., lake trout, walleye, Pacific salmon, and other sport and commercial fish) that feed on these prey fish. To enhance survey estimates of prey fish populations, the program is expanding to include assessments of pelagic (openwater) fish species using remote sensing technology. Staff are also evaluating the experimental design to provide even better estimates of prey fish abundance and biomass. Since prey fish may be limited by their invertebrate prey as well as by predator populations, scientists also incorporate invertebrate community assessments in survey designs. This important monitoring project enhances our understanding of the processes that shape the fish community and identifies characteristics critical to each species. The resulting long-term data set also can be used for a variety of long-term ecological studies, and enables scientists to address the importance of scale (within lake, between lakes, across basin) in ecological research questions.

Biomonitoring of Environmental Status and Trends (BEST). Since 1995, BEST has assessed fish health and contaminants in the Nation's large rivers. As of late 2004, BEST staff had conducted sampling at over 95 sites within the Columbia, Colorado, Yukon, Rio Grande, and Mississippi River basins. This work documents the impacts of environmental contaminants on fish in large rivers, including reproductive, pathological, and molecular indicators and fish health. BEST also documents and provides training to USGS scientists on several biomarker techniques. For example, monitoring results have identified potential endocrine disruption in large river fish in some sections of the Upper Mississippi River, prompting the USGS and associated state agencies to launch investigations into the causes.

National Park Monitoring. USGS scientists assist national parks with inventory and monitoring protocol development and monitoring-related research needs. Emphasis is on priority issues identified by the National Park Service (NPS) that typically involve and benefit several parks and require multiyear efforts. This work began as the USGS part of the cooperative NPS/USGS Long-Term Ecological Monitoring (LTEM) Program at 11 parks, which were selected by NPS as "prototypes" of specific biomes. Responsibility for a given park is assigned to the closest USGS Science Center with appropriate expertise. During the initial research and design phases of long-term monitoring at that park (usually 3-5 years), the USGS provides funding and full-time staff. After completion of research and protocol designs, monitoring is considered operational, and NPS assumes responsibility.

Status and Trends Assessments. The Status and Trends Program has periodically published comprehensive reports that synthesize our understanding of the Nation's biological and ecological resources (Mac and others, 1998; LaRoe and others, 1995). 
etc.), spatial (local, regional, national, global), and temporal (annual, decadal, etc.) scales. A systems approach to monitoring will prove beneficial in the long run by allowing scientists and managers to assess monitoring data in the context of the surrounding ecosystem conditions, with its attendant biotic and abiotic influences, and to recognize patterns not readily apparent when focused only on the smaller scales. Because ecosystem management protects the biodiversity of entire systems, assessing status and trends at the systems level is our long-range target. Although population monitoring is species-specific, there is a relationship between trends in species - particularly indicator or keystone species - and healthy, functioning ecosystems. Thus, increased monitoring of plant and animal populations is essential to understanding ecosystem change and management. Monitoring information must be improved so that it accounts adequately for at least keystone species and representative members of each community and habitat type (Mac and others, 1998).

\section{Human and Fiscal Resources}

Coalescing the separate, sometimes narrowly focused and long-standing monitoring activities of the USGS with other DOI bureaus, agencies, and organizations to enable a comprehensive assessment of the status and trends of biological resources is a challenging proposition. This challenge is made even more difficult given that, within this 5-year planning cycle, major funding increases are not anticipated. At the same time, operational costs (salaries, equipment, field work) increase annually. Advancement toward our goals will need to be undertaken with only modest or no additional funding. Yet, one of the priority staffing needs is to build scientific capacity for technical support in designing surveys

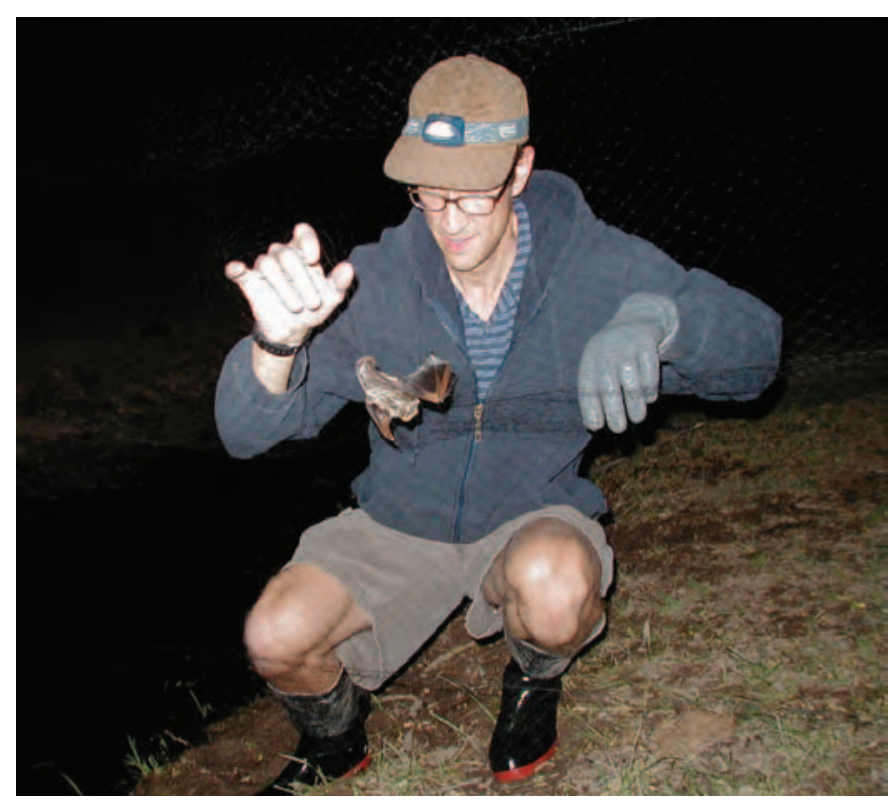

Mist-netting enables capture of bats for health assessment and population monitoring. Photo courtesy of Paul Cryan, USGS.

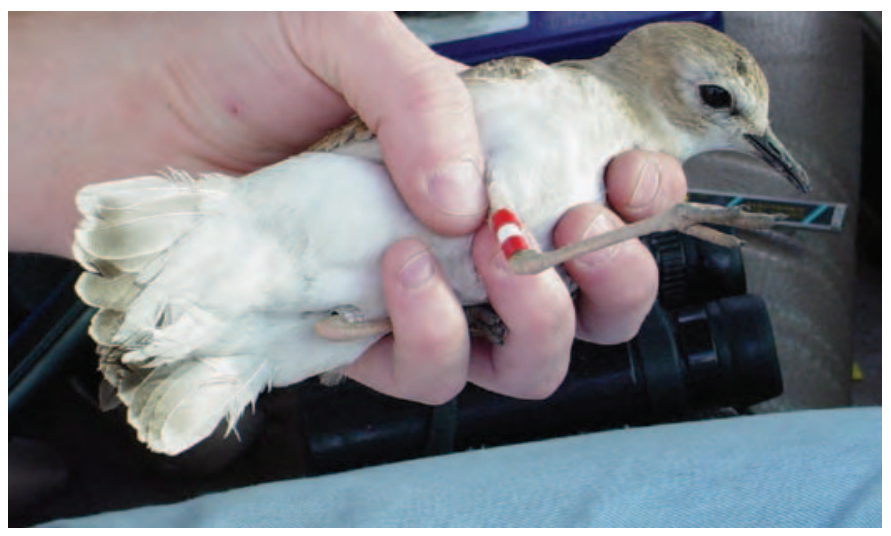

This Mountain Plover is wearing colored leg markers that can be viewed from a distance. This facilitates monitoring the bird's movements and other activities without the need for recapture. Photo by Fritz Knopf, USGS.

and monitoring protocols, incorporating appropriate statistical analysis methods, developing population models, and creating methodologies for evaluating the application of information to management. Ultimately, new resources will be required in order for this Plan to succeed and for the Program to reach its full potential.

Another challenge to the Program related to staffing is the perception that monitoring is less scientifically challenging than other scientific research, resource management, or any of the technical roles of the environmental scientist. Because of the repeated nature of monitoring activities, the field is viewed by some as being less creative or ingenious, thereby discouraging some scientists from pursuing monitoring in their professional careers (Mac and others, 1998). This perception may also explain the reluctance of professional supervisors to reward those who do. Once this Plan is implemented-when it begins to provide a structured approach to ensure that biological monitoring yields accessible, integrated, usable information, and its value to federal managers for informing resource management decisions is more broadly recognized - these perceptions should change.

\section{Where Are We Going?}

\section{A National Framework for Monitoring Biological Resources}

Both the Status and Trends Program Review (USGS, 1999) and the National Research Council (NRC, 1993) recommended that the Program develop a national framework for monitoring biological resources. Development and implementation of this National Monitoring Framework will improve our understanding and enable sound stewardship of the Nation's biological resources and the ecosystems that support them. To this end, the Program will work with willing collabo- 
"The value of statistical indicators for measuring performance, demonstrating accountability and assuring that key policy objectives are being met is well recognized. Good indicators also provide useful information for public discussion about national goals and priorities and the effectiveness of policies and programs. Conflicts over competing uses of natural and environmental resources can often be reduced by providing better information on conditions and trends."

CEQ (2002) rators to develop a conceptual model and the required partnerships to facilitate the acquisition, sharing, and integration of scientifically valid status and trends information across multiple spatial and temporal scales. In partnership with collaborators, a document will be developed describing the elements

that constitute the Framework (i.e., data generators, data users, information infrastructure, data reporting protocols, etc.), the organizational relationships among them, and their contribution to the accomplishment of existing and emerging biological resource monitoring goals. Specifically, the Framework will (1) increase collaboration in data collection to minimize duplication of effort; (2) better integrate data across taxa and ecological and geographic scales; (3) identify research and information needs; (4) promote new methodologies and analytical techniques; (5) support operational monitoring activities; and (6) enhance our ability to predict, assess, and report the status and trends of our Nation's biological resources.

The Framework will be a "living" construct, neither static nor unchanging, that is periodically reviewed and refined to meet new information needs, respond to organizational changes and challenges, and reflect budgetary realities. Such a Framework will foster improved programmatic efficiencies and economies of scale through better collaboration than currently exists among public and private organizations. This

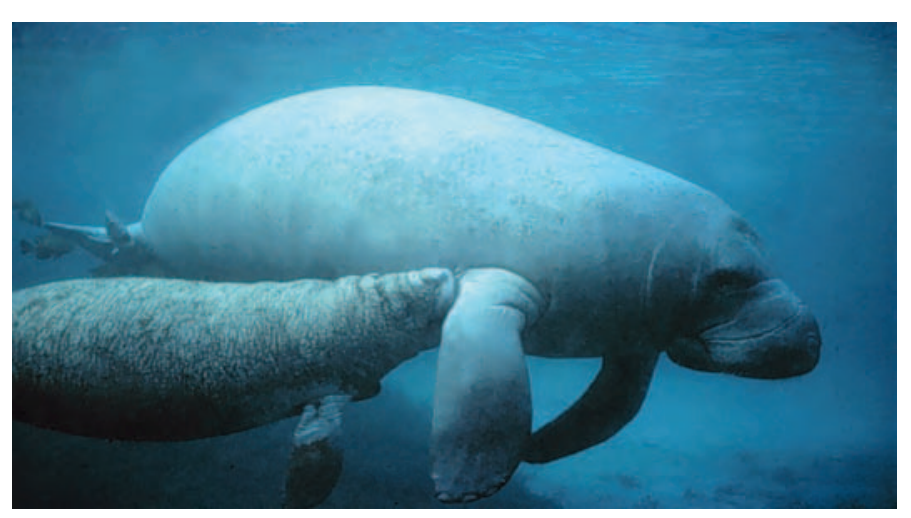

Individual manatees, like this female and her calf, can be identified by their unique scar patterns, usually a result of collisions with boats. Monitoring populations of this endangered species provides input to decisions concerning management of manatee habitat. Photo by Galen Rathbun, Sirenia Project, USGS.

collaboration, in turn, will render a more comprehensive and efficient information base from which to make planning and operational decisions, thereby strengthening the quality of such decisions and ultimately improving the management of biological resources. In the long term, such an extensive and common information base could be used to anticipate and reduce or mitigate potential conflicts over managing these resources. "A Vision of the Future" (see box, page 8) provides a scenario of how this might work, using one specific example.

\section{How Will We Get There?}

Given the many challenges, fully achieving the mission of the Program will take time. Progress will be measured in small, modest gains as scientists and resource managers gradually begin to embrace a new way of doing business and build toward a common, unified approach to monitoring the status and trends of biological resources. Over the next 5 years, progress made in implementing the priority objectives for each Program goal, described below and in Tables 1 and 2, will gauge our success.

All of the following goals and priority objectives involve partnering to coordinate and integrate information collection, management, and dissemination. Such cooperation and collaboration, built purposefully and steadily over time, is essential to goal achievement.

\section{Goal 1: Develop a Conceptual Model and the Required Infrastructure (A National Monitoring Framework) that Facilitates the Integration of Information from a Variety of Sources, at Multiple Spatial and Temporal Scales, to Describe and Track the Abundance, Distribution, Pro- ductivity, and Health of the Nation's Plants, Animals, and Ecosystems}

Even with partner collaboration, developing and implementing a Framework as described above will require more than the 5 years this Plan covers. However, we can take several significant steps in this time period to move substantially closer to this goal. Our initial objectives are these:

Objective 1A. Identify current inventory and monitoring activities (what, where, why, how, when, by whom, and data accessibility).

Objective 1B. Improve coordination among USGS monitoring activities.

Objective 1C. Improve communication and coordination between the Program, partners, and stakeholders.

Objective 1D. Develop a Framework for monitoring selected biological resources/indicators.

Objective 1A involves working with partner agencies and organizations to inventory and understand the nature of ongo- 


\section{A Vision of the Future}

A biologist is working to restore 100 acres of dense willow on a major river to benefit nesting neotropical migrant songbirds (yellow warbler, willow flycatcher) and resident moose, river otter, and beaver. To evaluate success of the management strategy, the biologist must implement a vegetation monitoring plan. A wildlife monitoring plan will also be required to document changes in wildlife use and correlate these changes to changes in habitat.

The biologist has access to a variety of technical reports, both in print and on the Web, detailing the status and trends of the species of interest at the national and regional levels. On the Web, she can conduct custom analyses of the status and trends of critical species in the area surrounding the management unit using data from national monitoring surveys.

To design a monitoring program, the biologist accesses the Status and Trends Web site that is supported by and populated with information from all partners (federal, state, tribal, and local governments; academic and research institutions; and private organizations). There she reviews a list of peer-reviewed, scientifically valid methods designed to address specific types of resource questions. The site is continually updated with new applications. In this case the biologist reviews the monitoring issues pertaining to the restoration of riparian habitats along major rivers in the central U.S. Expert systems are available to assist in determining what ques-

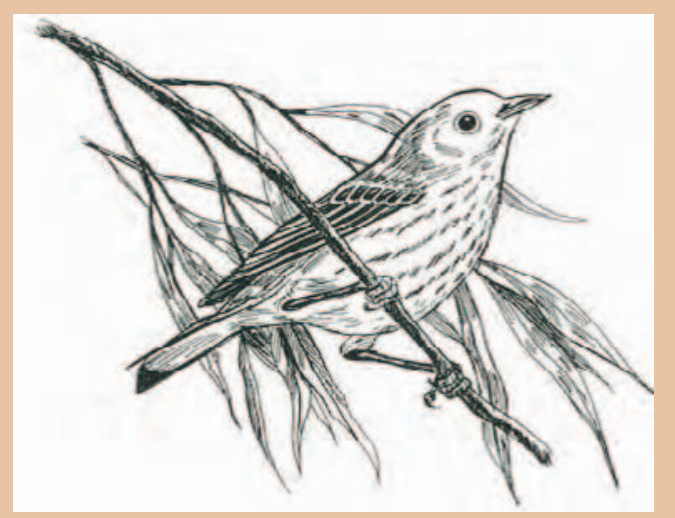

Yellow Warbler. Drawing by Dale Crawford tions should be addressed, how the sampling design can be applied, what data collection methodologies should be used, and what data analyses are appropriate. A data entry format is provided. She fills it in, and a statistically valid monitoring protocol, responsive to the issues and questions entered, is generated. Comments and suggestions are available from developers and users of the methods as to their strengths and weaknesses. Should additional questions remain, the biologist may use an on-line help link to seek further technical assistance or direct questions to appropriate technical experts. She can then implement the monitoring effort.

In the field, the biologist enters the collected data following the data entry format associated with the protocol, and the information is sent directly to a distributed database maintained by her particular management agency and accessible to others via the National Biological Information Infrastructure (NBII). Expert systems and analytic tools appropriate for use with this protocol are available online to assist with the analysis.

Because common or comparable methods are used, the data may be integrated across multiple spatial and temporal scales. Now the biologist can assess how the observed changes in yellow warblers found on her management unit compare to changes in yellow warblers across their entire range. The broader research community can combine information from this management unit with other data to model and assess biological communities in the river basin, or the flyway. Models developed to assess the system dynamics and variability of the river basin incorporate information on the biological, hydrological, geological, geographical, social, and economic changes occurring within the system. These results are also made available to the biologist to help explain the broader impacts of her unit's specific management actions. 
ing biological monitoring programs. To accomplish Objective $1 \mathrm{~B}$, communication within the USGS will focus on coordinating and integrating information acquired through other Bureau monitoring activities with each other and with USGS research capabilities in order to advance the mission of the Program.

To implement the NRC (1993) recommendations and meet Objective 1C, the USGS will promote and facilitate dialogue among partners to (1) share and increase the collective knowledge concerning the status and trends of biological resources, and (2) work together to develop and advance a Framework to better understand these critical resources. Objective 1D will extend this Plan to include our partners in developing a joint strategy for monitoring critical resources and harmonizing existing efforts.

\section{Goal 2: Develop and Evaluate Inventory and Monitoring Methods, Protocols, Experimental Designs, Analytic Tools, Models, and Technologies to Measure Biological Status and Trends}

Achieving a holistic approach to monitoring the status and trends of biological resources will require that methodologies are current, appropriate to their intended purpose, well documented, scientifically sound, and to the extent possible, compatible among studies. The Program Review (USGS, 1999) recommended that the Program should be "the agency leader for the development of basic biological inventory and monitoring protocols...including data quality and analytical standards for monitoring programs."

In addition, the Program should network and cooperate with DOI and other public and private organizations conducting research programs that involve developing biological inventory and monitoring tools and techniques.

Toward these ends, the Program's 5-year priority objectives for meeting this goal are as follows:

Objective 2A. Work with USGS staff, partners, clients, and others to identify, develop, evaluate, and publish methods, analytic tools, and models to measure the status and trends of biological resources.

Objective 2B. Work with USGS staff, partners, clients, and others to coordinate and promote valid, consistent, and

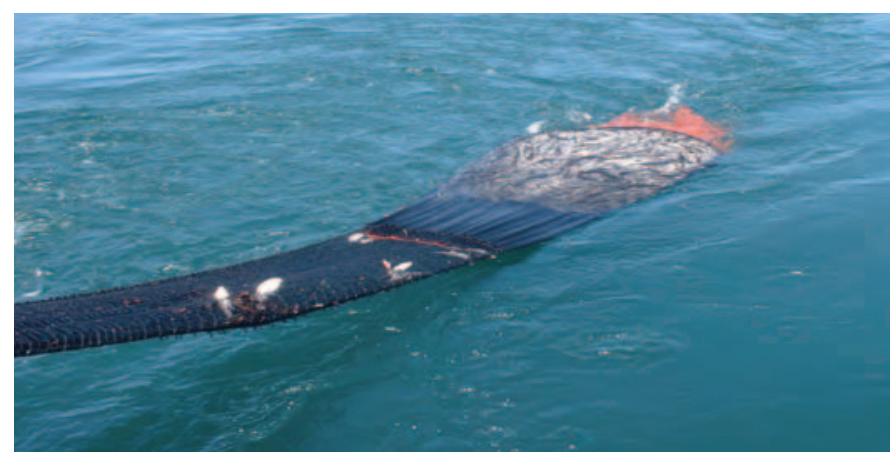

A USGS research vessel operated by the Great Lakes Science Center captures fish in a bottom trawl on Lake Huron. USGS photo.

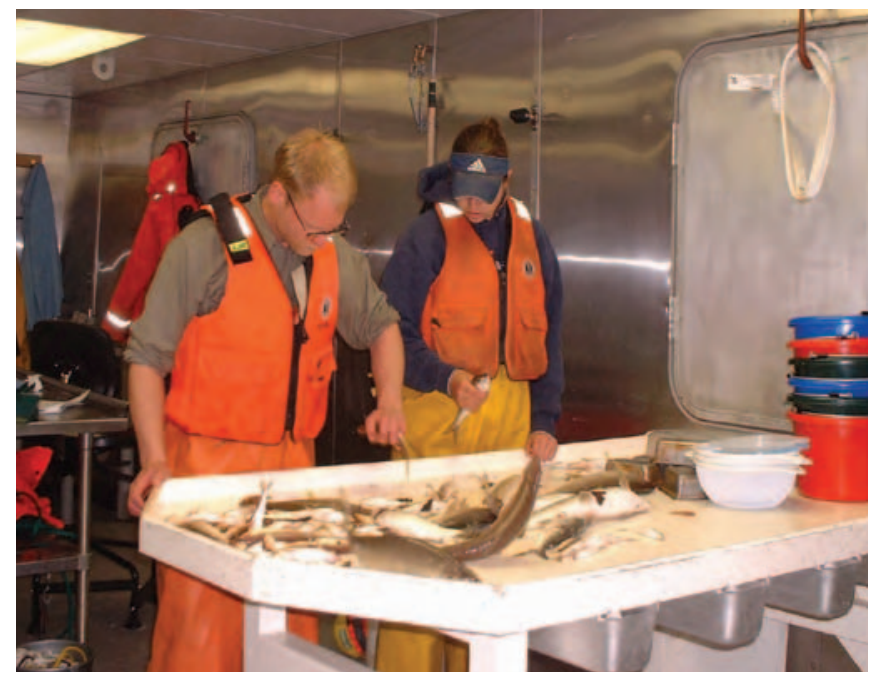

Technicians sort a bottom trawl sample by size (age) and species as part of the Great Lakes Fish Stock Assessment. USGS photo.

comparable inventory and monitoring designs and methods across USGS regions, among agencies, and between governmental and non-governmental programs.

Objective 2C. In cooperation with partners, periodically review Program monitoring activities to ensure continued relevance and scientific rigor.

\section{Goal 3: Collect, Manage, Archive, and Share Critical, High-Quality Monitoring Data in Cooperation with Part- ners to Enable a Determination of the Status and Trends of Biological Resources}

The existing monitoring activities are at the heart of status and trends work, and the USGS is committed to continuing the data collection activities that are core to its mission (USGS, 2002). This commitment aligns with the Program Review (USGS, 1999) recommendation that the Program continue to implement its operational inventory and monitoring program, but also develop and implement appropriate new

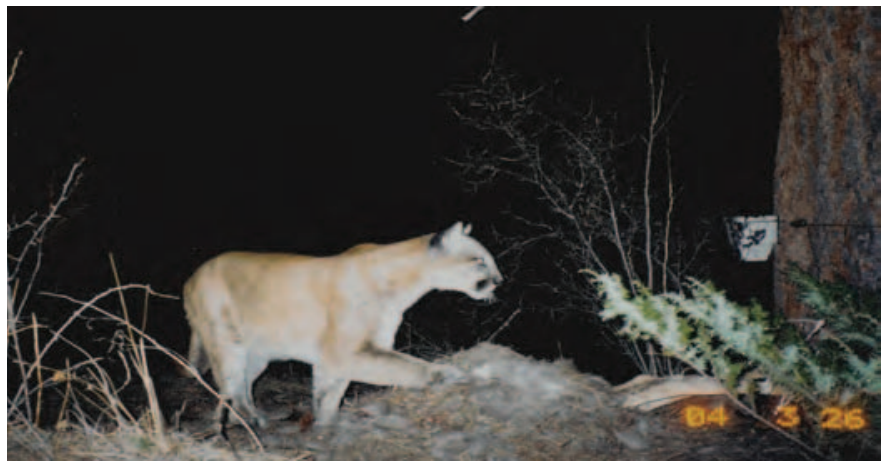

A mountain lion takes a self portrait with a self-triggering camera at a kill site. Non-invasive monitoring methods for these elusive animals are being developed to better understand their movements and behaviors, especially in popular national parks in the West. USGS photo. 
projects. Here again, the Program will network with other agencies and organizations engaged in biological inventory and monitoring to become aware of what is already available, and to identify gaps where further investments are warranted. Accordingly, we developed the following objectives:

Objective 3A. Continue, expand, and improve Program monitoring efforts.

Objective 3B. Identify and promote best practices for managing status and trends data and metadata for quality assurance, database design, and data storage and exchange.

Objective 3C. Promote access to inventory and monitoring data and interoperability of databases.

Much of the work to achieve these objectives will be conducted in partnership with other federal, state, tribal, and private agencies and organizations. For example, the National Biological Information Infrastructure (NBII), developed and maintained by the USGS, is actually a consortium of government agencies, academic institutions, non-government organizations, and private industries collaborating to provide increased access to data and information on the Nation's biological resources. The NBII links diverse, high-quality biological databases, information products, and analytical tools maintained by NBII partners and other contributors. Working through programs and partnerships like these to improve biological monitoring and data access and management will allow the Program to deliver higher-quality information that natural resource managers, the research community, and the public can easily retrieve and apply.

\section{Goal 4: Produce and Provide Analyses and Reports that Synthesize Information on the Status and Trends of Our Nation's Flora, Fauna, and Ecosystems and Respond to the Needs of the Scientific Community, Land and Resource Managers, Policymakers, and the Public}

Finally, the Program will assess information collected and produce reports that are relevant to resource management and biological research needs. The Program will use information made available from compatible programs in other agencies and will collaborate with these partners, where appropriate, in producing more comprehensive, integrated, and applicable analyses and reports. Hence, these objectives:

Objective 4A. Provide print and Web-accessible reports, syntheses, and other information to advance greater

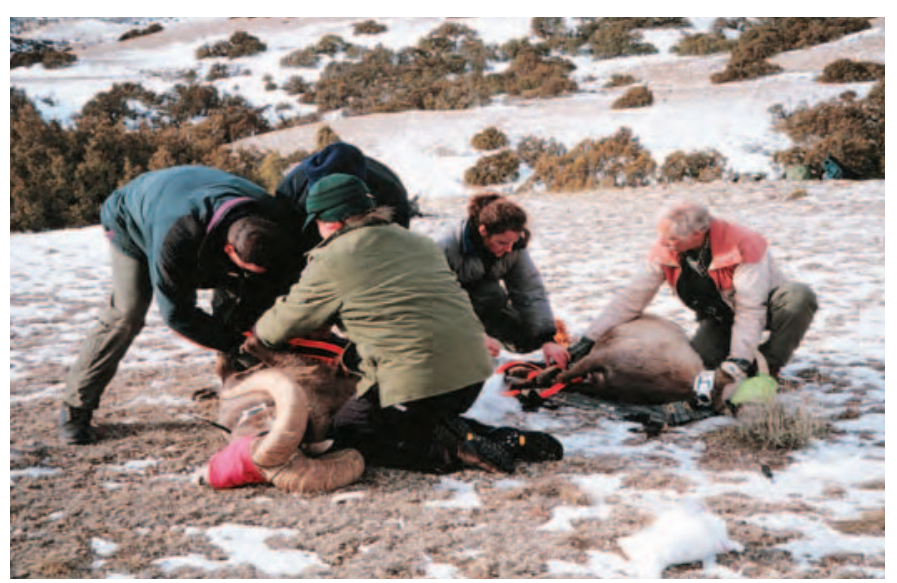

Tranquilized bighorn sheep get a health check and radio collars for tracking herd movements. USGS photo.

understanding, interpretation, and use of status and trends information.

Objective 4B. Provide information and technical support relevant to DOI and other resource management agency and stakeholder needs.

Our objectives involve continuing and improving the delivery of information products, technical assistance, and other services related to inventory and monitoring. These products and services will focus on answering questions posed by DOI resource managers and the broader resource management and scientific community. Timeliness and ease of access are high priorities for making this information available, and emphasis will be placed on serving data from multiple sources on the Web to reflect information and knowledge on the status and trends of the Nation's biological resources at local, regional, and national scales.

\section{Implementation}

Implementation of this Plan (Tables 1 and 2 and Figure 1) will be a significant step toward achieving our Program mission. Progress will be marked by the necessity to revise and update this Plan to reflect new objectives as old ones are met. It will also be manifested in the expansion of committed partners who will work collaboratively to develop a National Monitoring Framework, collecting and sharing data, information, and knowledge on the status and trends of our biological resources. 


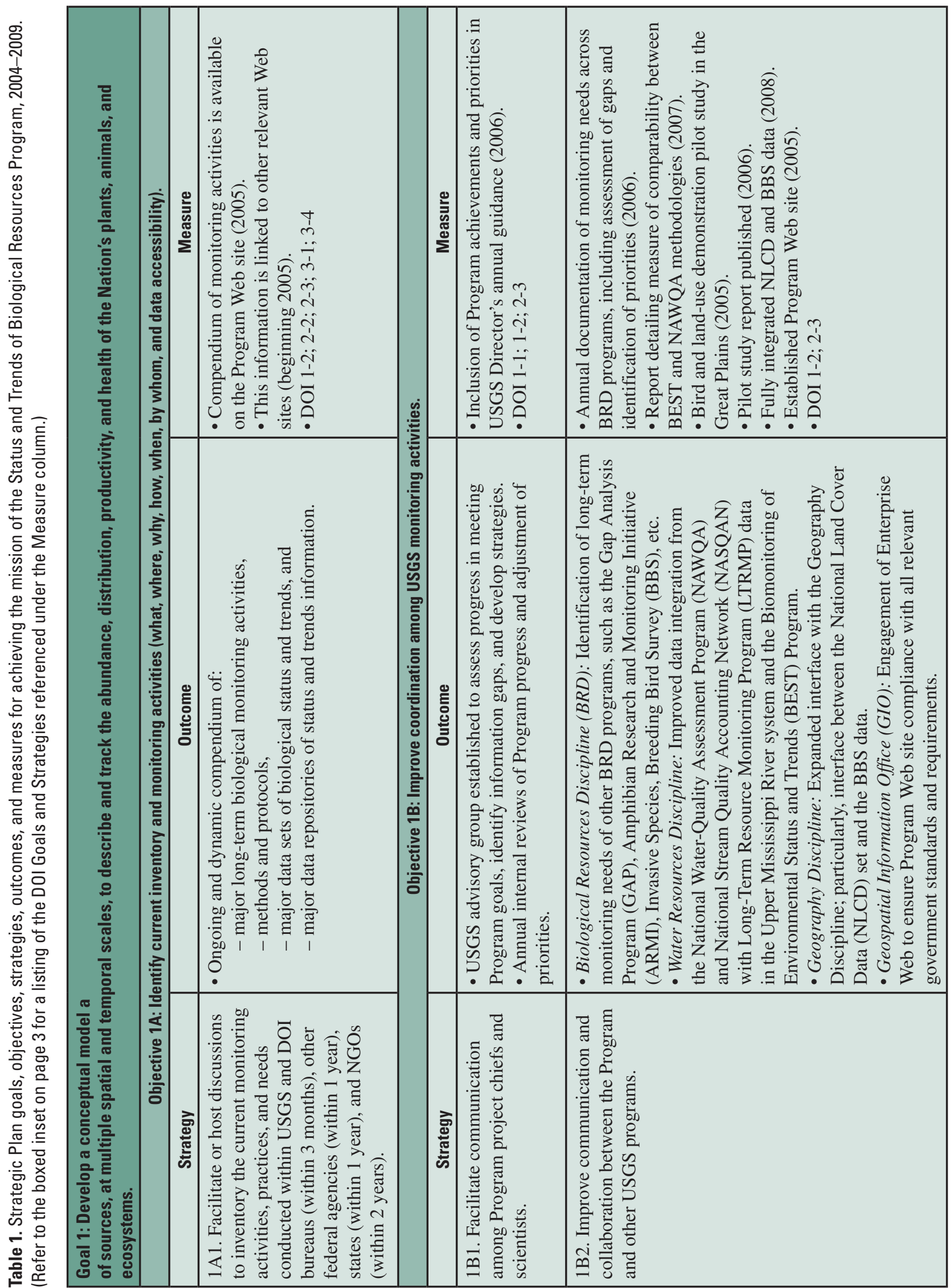




\begin{tabular}{|c|c|c|c|c|}
\hline & 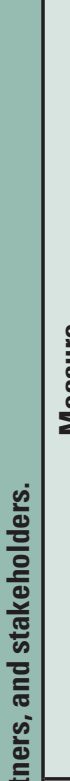 & & 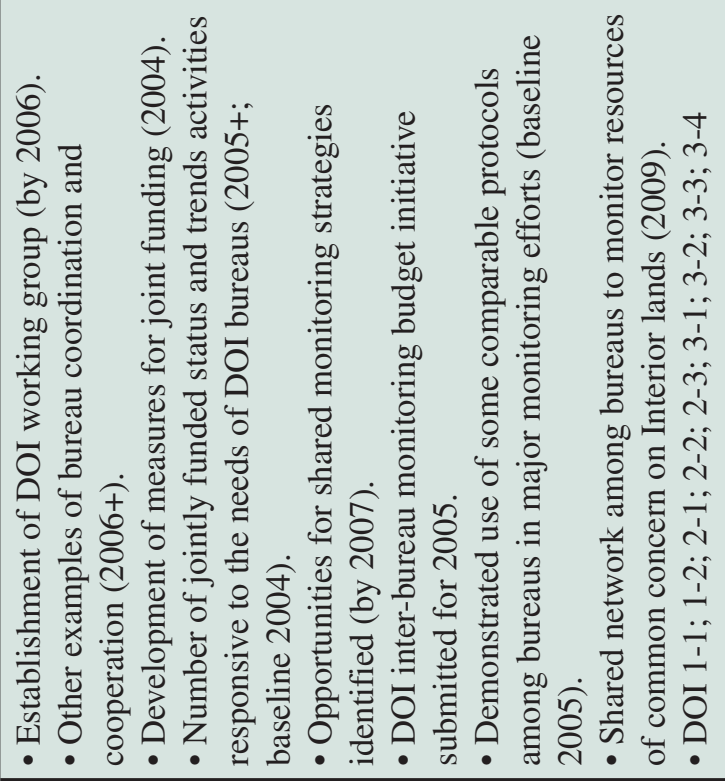 & 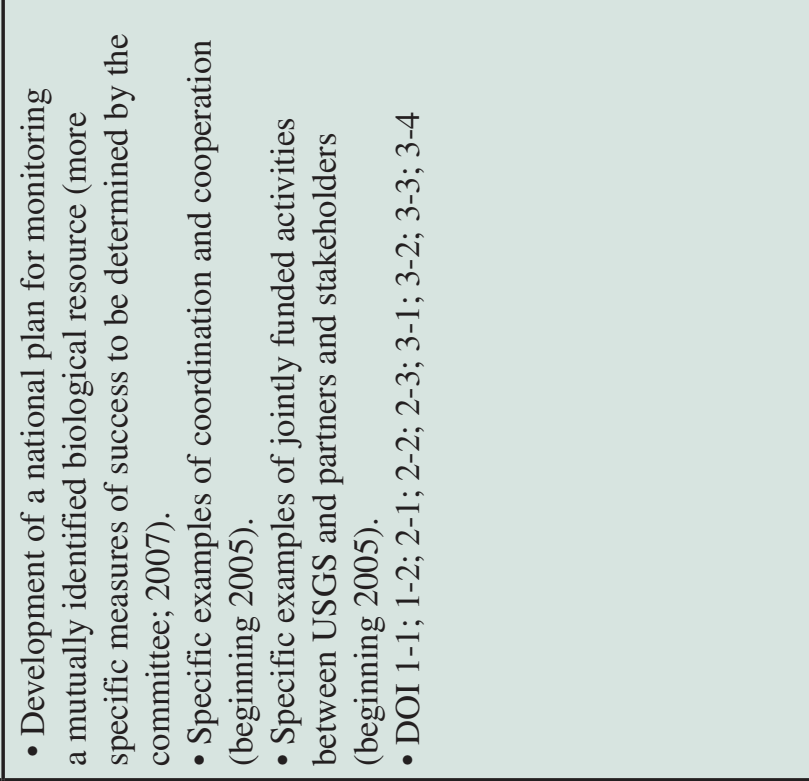 \\
\hline 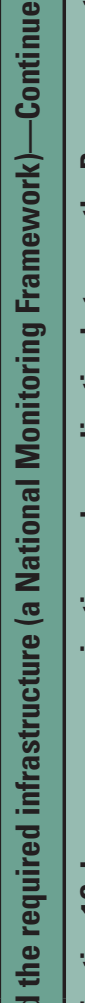 & 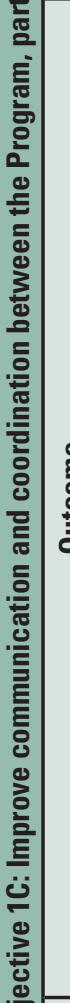 & 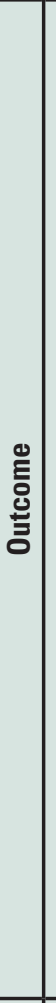 & 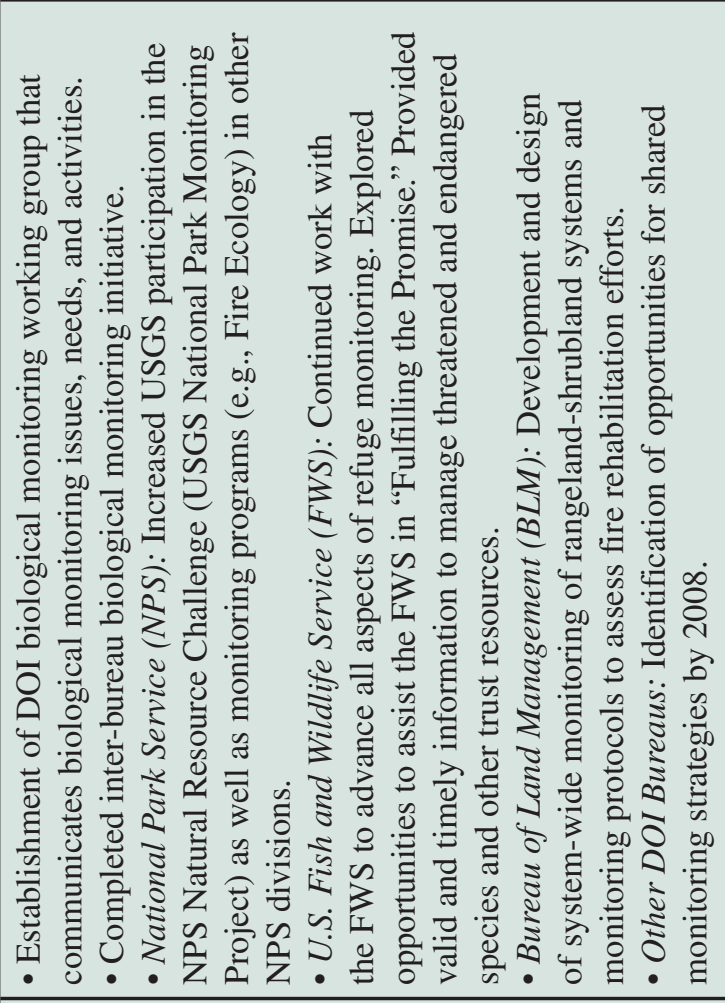 & 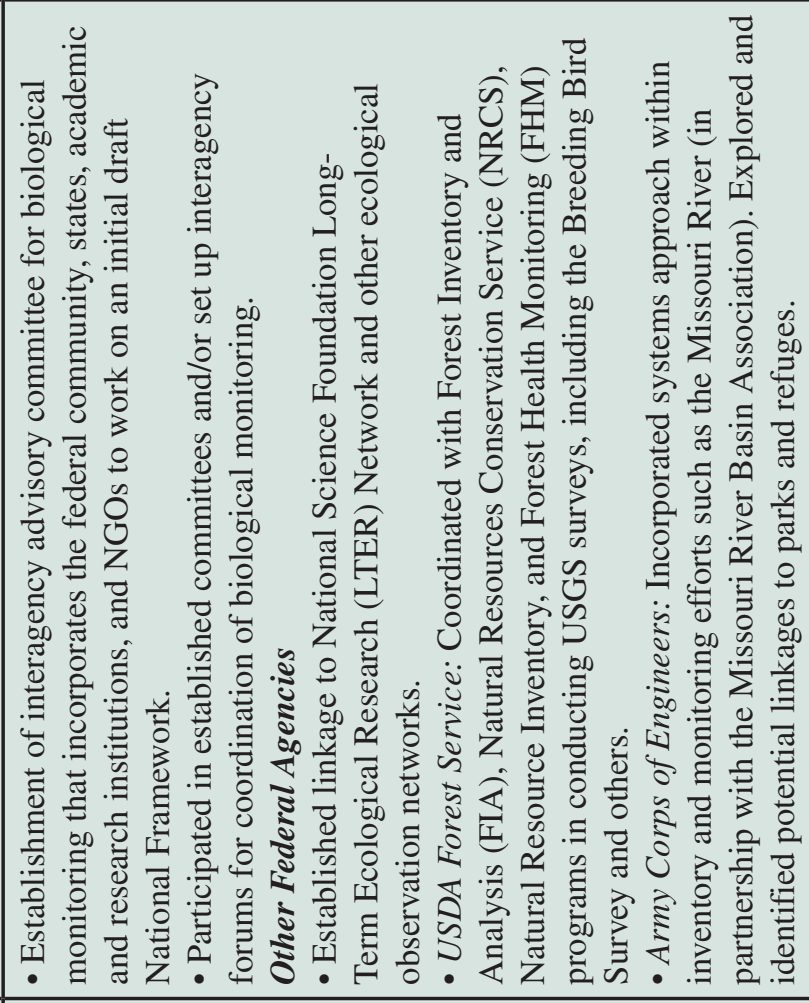 \\
\hline 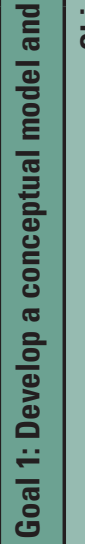 & 兑 & & 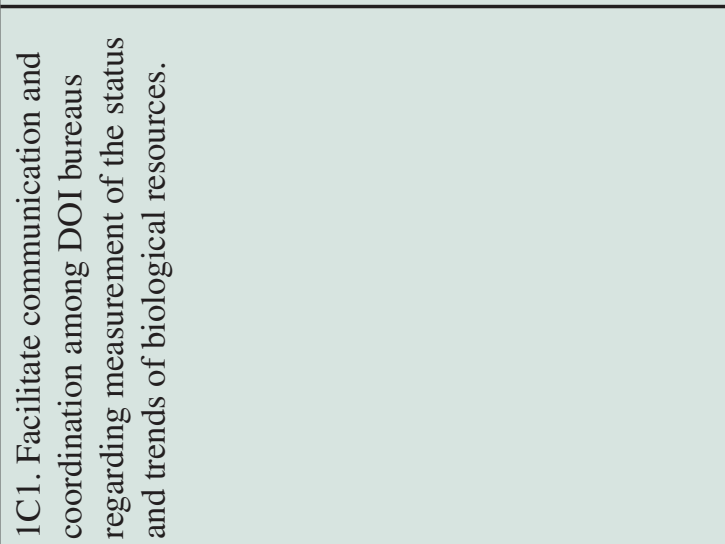 & 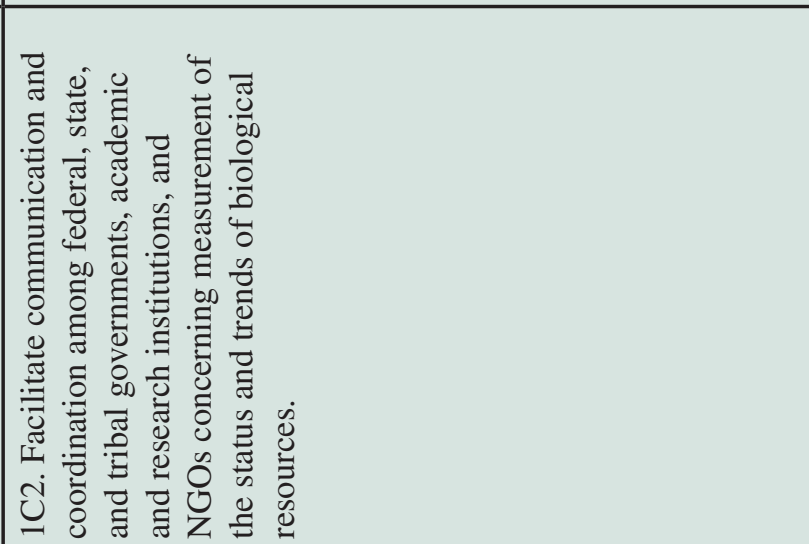 \\
\hline
\end{tabular}




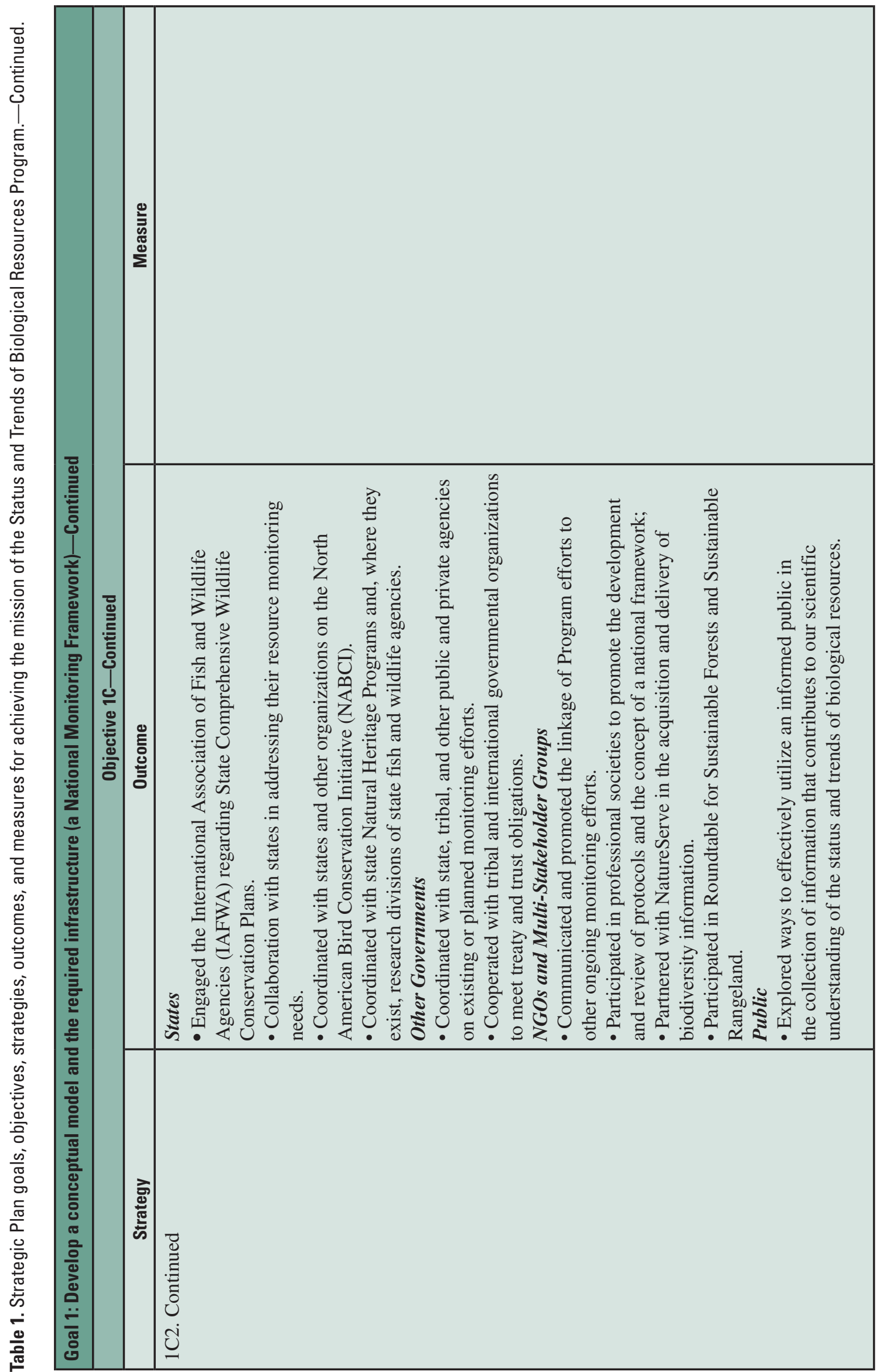




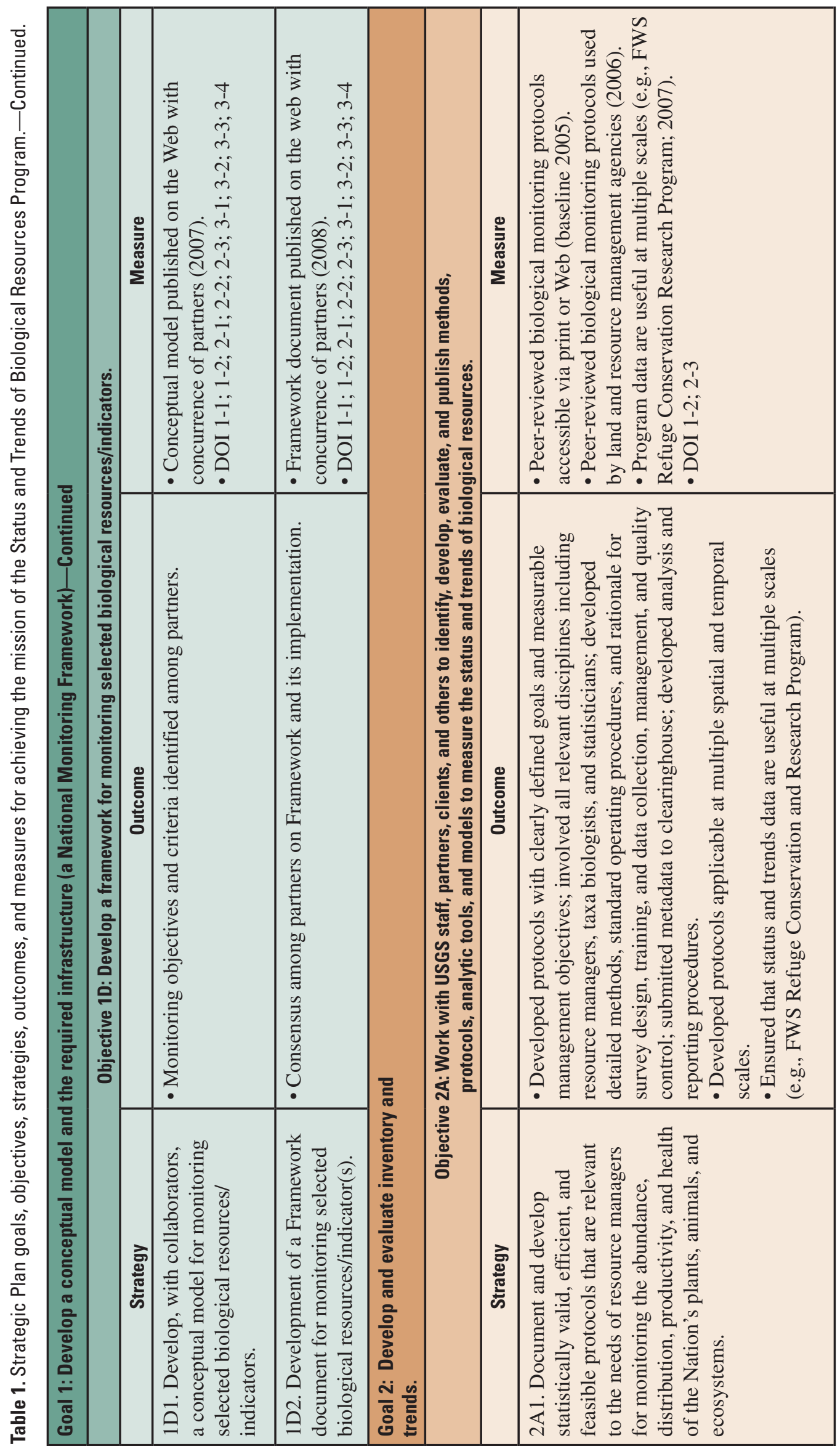




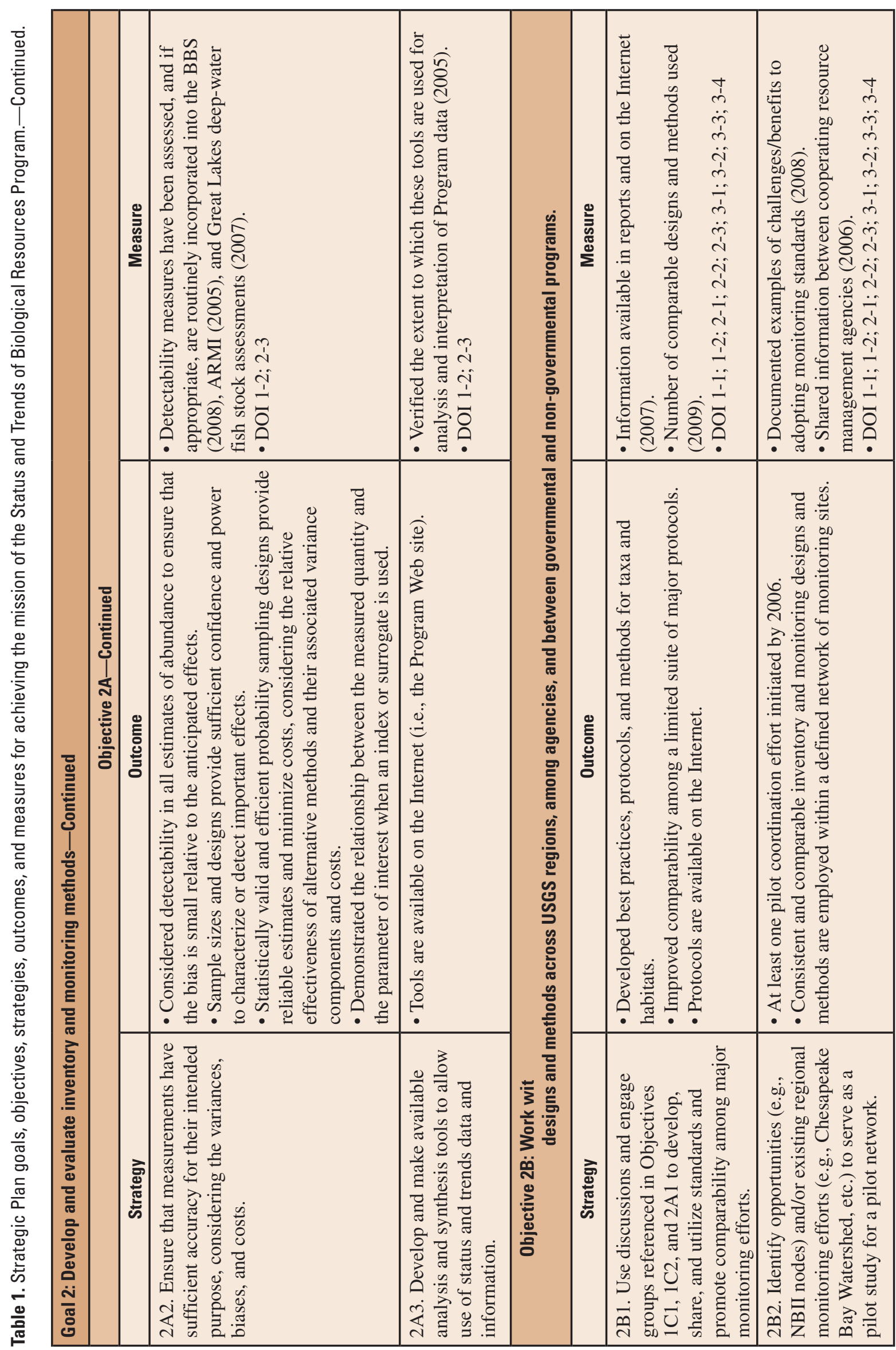




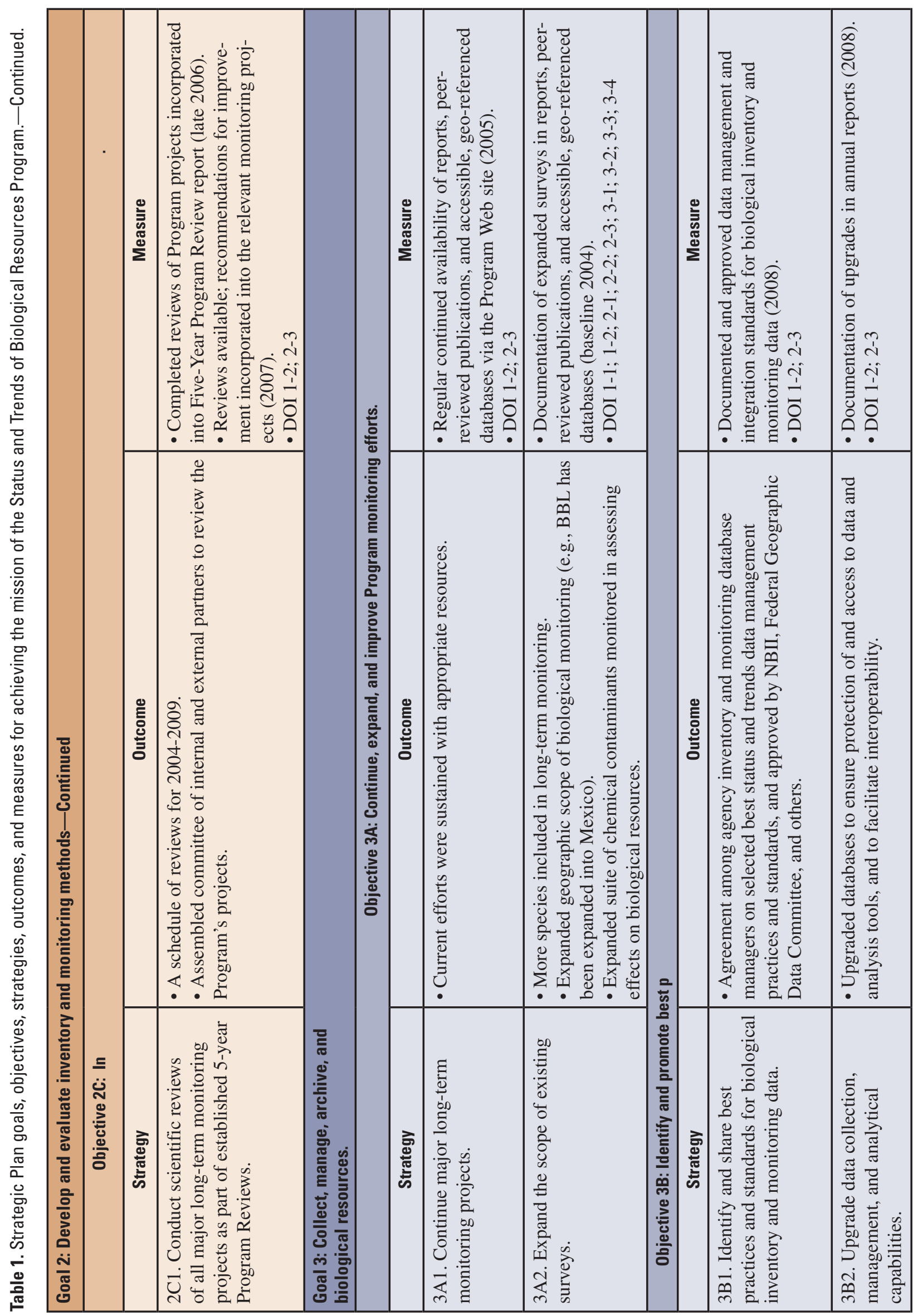


Table $1 \quad 17$

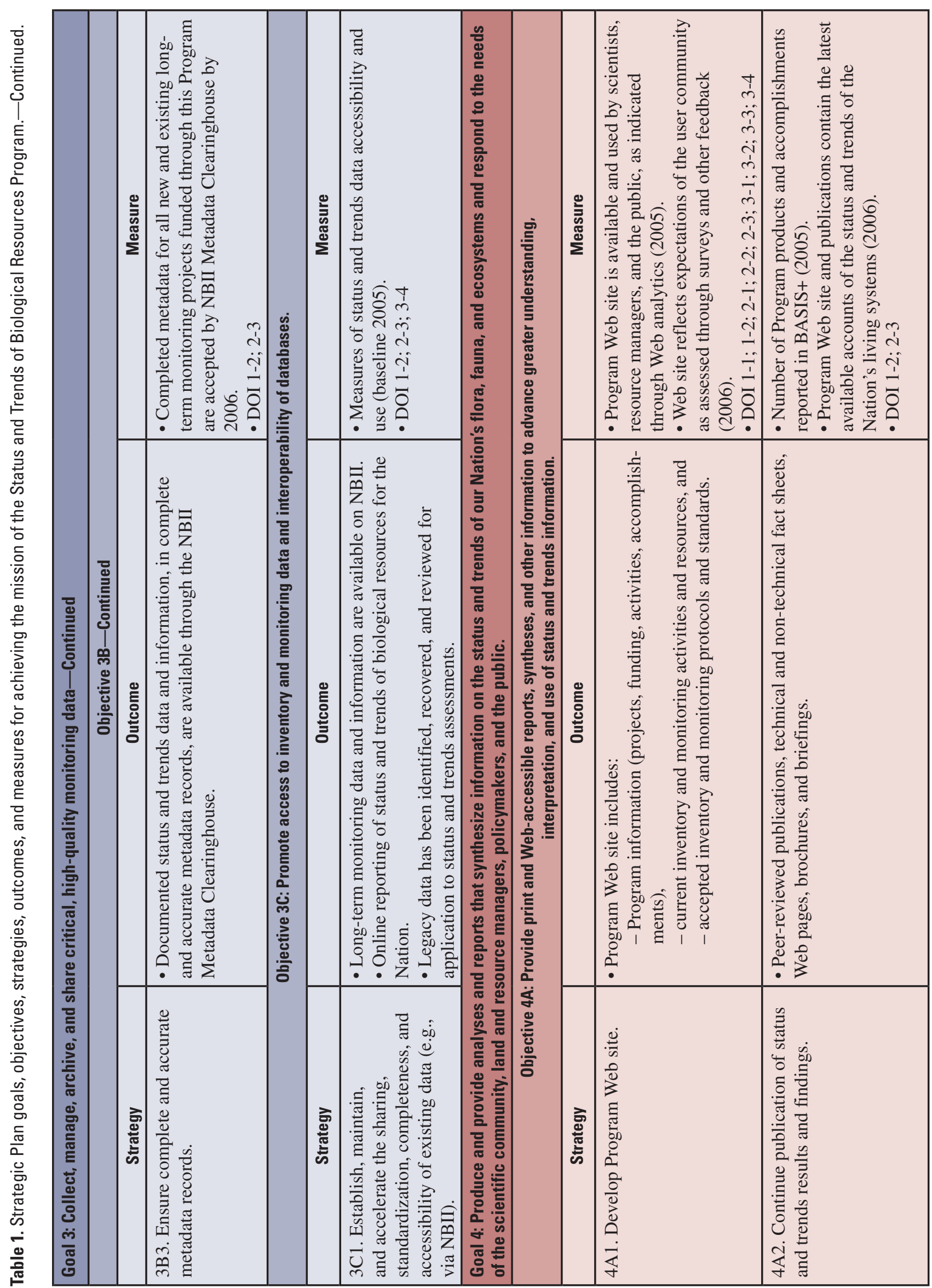




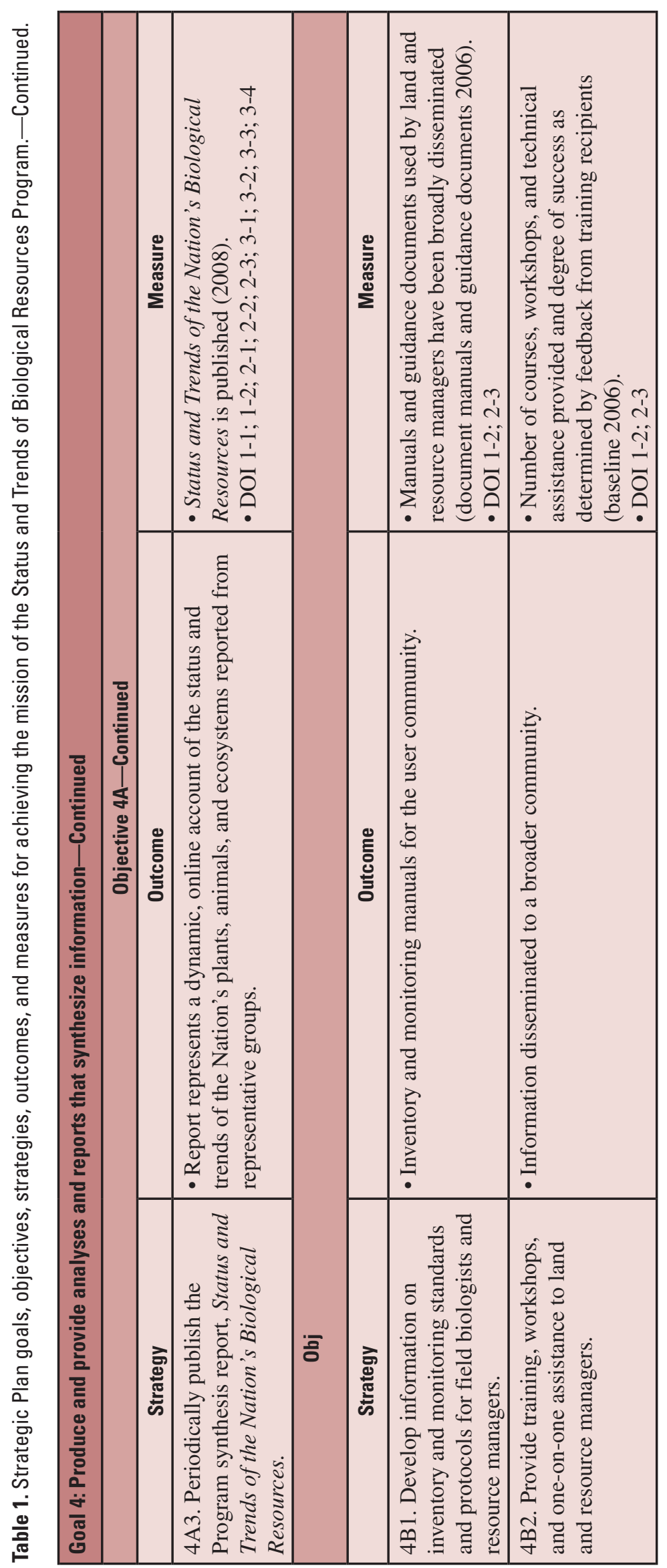




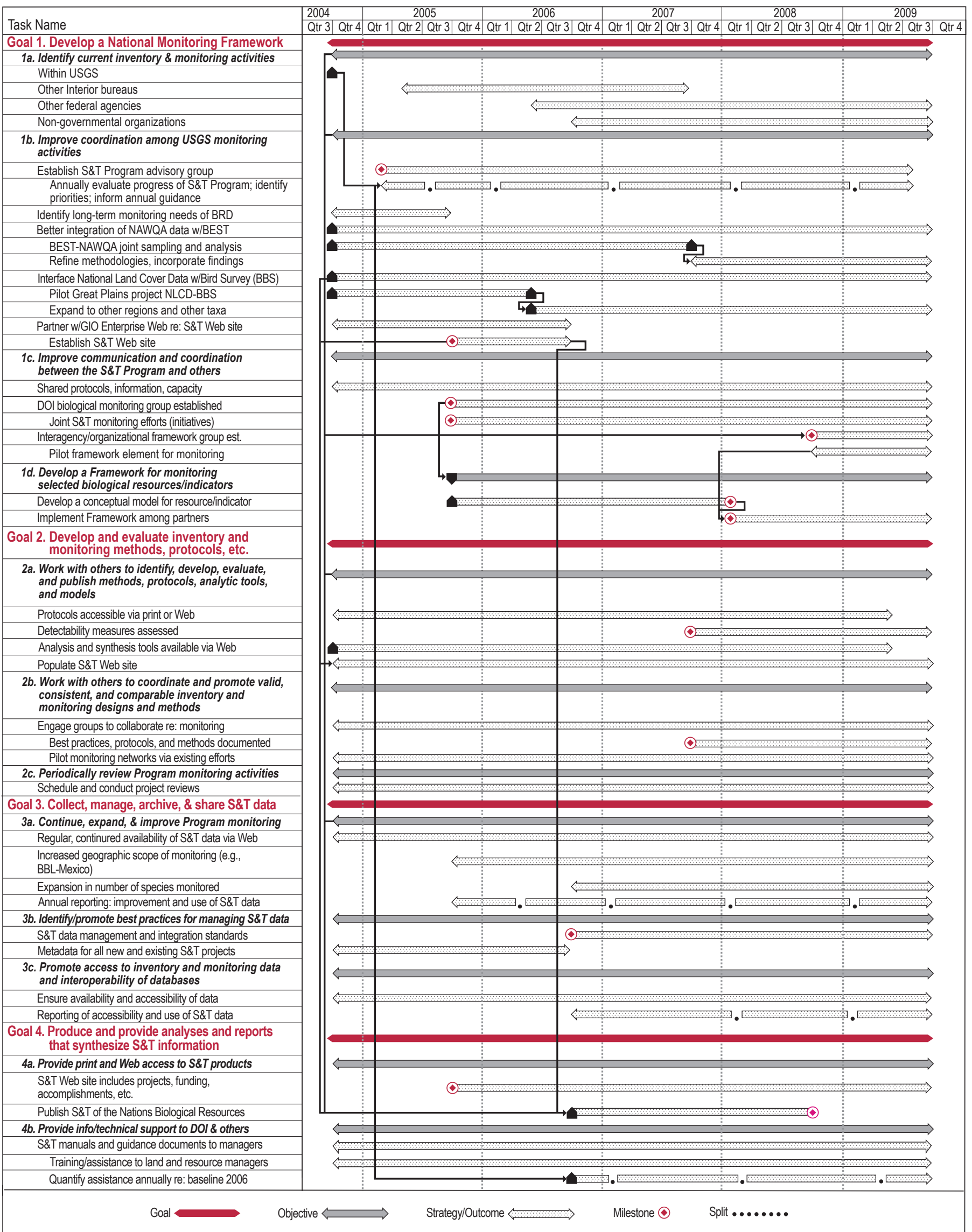

Figure 1. Summary and timeline of Status and Trends Program goals, objectives, outcomes, measures, and milestones: 2004-2009. 
Table 2. Recommended directions by taxa and theme for advancing Program goals.

\begin{tabular}{|c|c|}
\hline Taxon/theme & Recommendations \\
\hline Birds & $\begin{array}{l}\text { Incorporate measurement detection probability into survey design of the BBS; ensure } \\
\text { adequate bird band supply for the BBL; increase the number of species monitored by long- } \\
\text { term surveys; expand the geographic scope of existing surveys; improve the bird population } \\
\text { database infrastructure and data delivery; contribute to the bird status and trends objectives of } \\
\text { NABCI. }\end{array}$ \\
\hline Fish & $\begin{array}{l}\text { Develop a strategic plan for fish monitoring in the Great Lakes, Mississippi River systems, } \\
\text { Grand Canyon, and Colorado River; incorporate fish monitoring programs into databases for } \\
\text { exotic species; develop methods to provide easy access to fish monitoring data of the Great } \\
\text { Lakes and Colorado River; assess feasibility of hydroacoustic monitoring methods in the } \\
\text { Great Lakes; implement a monitoring system for the Missouri River. }\end{array}$ \\
\hline Mammals & $\begin{array}{l}\text { Compile, evaluate, and summarize activities to measure and assess the status and trends } \\
\text { of mammalian species on a state-by-state basis; evaluate current activities for managerial } \\
\text { relevance (e.g., chronic wasting disease) and statistical rigor; analyze these activities for } \\
\text { estimation of status and trends; report to states the findings of the efforts leading to improved } \\
\text { methods, collaboration, and partnerships. }\end{array}$ \\
\hline Invertebrates & $\begin{array}{l}\text { Explore use of taxonomic services through the USGS Water Quality Laboratory to identify } \\
\text { aquatic invertebrates, and through the Smithsonian, academic institutions, and USGS } \\
\text { scientists to identify terrestrial invertebrates; develop standard sampling strategies for aquatic } \\
\text { and terrestrial invertebrates; investigate the utility of using NAWQA invertebrate data to } \\
\text { assess status and trends of aquatic invertebrates; develop a strategy to assess status and trends } \\
\text { in terrestrial invertebrates; work toward a common protocol and shared Program information } \\
\text { base with emphasis on pollinators, soil food-web organisms, and freshwater mussels. }\end{array}$ \\
\hline Amphibians and reptiles & $\begin{array}{l}\text { Enhance the capabilities of existing amphibian monitoring efforts; better utilize and } \\
\text { coordinate the complementary approaches of the North American Amphibian Monitoring } \\
\text { Program and ARMI to yield improved estimates of the status and trends of amphibians; } \\
\text { explore the establishment of a framework for monitoring status and trends of reptiles. }\end{array}$ \\
\hline Plants, lichens, and mosses & $\begin{array}{l}\text { Work toward development and evaluation of regional protocols for inventory and assessment } \\
\text { of plant, lichen, and moss status and trends; develop and evaluate national protocols for their } \\
\text { status on U.S. grasslands, woodlands, forests, and rangelands (e.g., Forest and Rangeland } \\
\text { Roundtables). }\end{array}$ \\
\hline Imperiled species & $\begin{array}{l}\text { Maintain capability for determining status and for monitoring and predicting trends for } \\
\text { federally listed species, candidate species, and species of concern. Increase accessibility to } \\
\text { imperiled species data from multiple sources. }\end{array}$ \\
\hline Ecosystems & $\begin{array}{l}\text { Tie species status and trends to ecological systems. Map ecological systems and habitat } \\
\text { quality over time, corresponding to species population status and trends (which species are } \\
\text { declining, stable, improving per habitat type, over time). Work toward using knowledge base } \\
\text { (species-system status and trends) to begin identifying key sets of indicators of ecosystem } \\
\text { status and trends; strive to formalize linkages to other ecosystem-related efforts such as the } \\
\text { LTER Network and the National Science Foundation's National Ecosystem Observation } \\
\text { Network (NEON). }\end{array}$ \\
\hline Genetics & $\begin{array}{l}\text { Develop guidance to incorporate genetic sampling as a standard monitoring tool; develop } \\
\text { cost-effective contaminant screening tools; develop an inventory/database of molecular } \\
\text { markers for trust species; incorporate genetic information within Program reporting vehicles. }\end{array}$ \\
\hline Microbes & $\begin{array}{l}\text { Host workshop to identify current and future approaches (e.g., genetic and molecular } \\
\text { techniques) to inventory and monitor microbial species/groups and their function in natural } \\
\text { systems. }\end{array}$ \\
\hline
\end{tabular}


Table 2. Recommended directions by taxa and theme for advancing Program goals. - Continued.

\begin{tabular}{|c|c|}
\hline Taxon/theme & Recommendations \\
\hline Contaminants & $\begin{array}{l}\text { Complete plans to increase the efficiency (leverage with other efforts) and spatial extent of } \\
\text { the BEST Program efforts to monitor and assess contaminant effects on fish in large U.S. } \\
\text { rivers; improve capability to integrate findings of BEST and NAWQA; establish, maintain, } \\
\text { and accelerate the sharing, standardization, completeness, and accessibility of existing data } \\
\text { on the distribution, concentrations, and effects of environmental contaminants by maintaining } \\
\text { and enhancing online databases; provide training to DOI bureaus on collection, use, and } \\
\text { interpretation of biocontaminants. }\end{array}$ \\
\hline Invasives & $\begin{array}{l}\text { Coordinate and promote consistent and comparable inventory and monitoring designs } \\
\text { and methods for invasives (e.g., early detection in ballast water); establish, maintain, and } \\
\text { accelerate the sharing, standardization, completeness, and accessibility of existing data on } \\
\text { invasive species via the NBII Invasive Species Information Node; use this Node as a vehicle } \\
\text { to promote a status and trends monitoring network for invasive species; provide technical } \\
\text { assistance to government and NGOs on all aspects of the inventory and monitoring of } \\
\text { invasive species. }\end{array}$ \\
\hline Human dimensions & $\begin{array}{l}\text { Provide ongoing assessments of the social, economic, and institutional implications of } \\
\text { resource use; monitor changing human development patterns; develop techniques to assess } \\
\text { the economic and social effects of environmental trends and conditions; design research } \\
\text { to guide use of socioeconomic data in decision making and better management of natural } \\
\text { resource conflicts. }\end{array}$ \\
\hline $\begin{array}{l}\text { Taxonomy and } \\
\text { systematics }\end{array}$ & $\begin{array}{l}\text { Provide taxonomic and systematic research and identification services on North American } \\
\text { biota to support status and trends activities; provide a credible, automated taxonomic } \\
\text { reference of North American biota; work to develop the interface between taxonomic/ } \\
\text { genomic data. }\end{array}$ \\
\hline Remote sensing & $\begin{array}{l}\text { Promote dialogue among the internal/external science community to enhance and improve } \\
\text { methodologies for use of remote sensing to address Program goals; work toward development } \\
\text { of standards for evaluation and consistency of remote sensing data and methodologies. }\end{array}$ \\
\hline Standards and protocols & $\begin{array}{l}\text { Ensure statistical and managerial input into standards and protocols; peer review and publish } \\
\text { (Web or print) protocols; enhance multidisciplinary nature of protocols that are guided by } \\
\text { conceptual models of the system/questions; strengthen the connection between survey goals } \\
\text { and protocols; ensure that protocols relate to all aspects of a survey, including analysis and } \\
\text { dispersion of information; incorporate measures of comparability among methodologies; } \\
\text { incorporate measures of detectability and confidence in survey/monitoring designs. }\end{array}$ \\
\hline Statistical tools and modeling & $\begin{array}{l}\text { Ensure that objectives for each Program activity are measurable and of sufficient clarity that a } \\
\text { reasonable observer may determine if an objective is achieved; demonstrate the feasibility of } \\
\text { each Program activity to produce valid and reliable results within existing resources; develop } \\
\text { methodologies to use status and trends data collected at variable scales to enable valid and } \\
\text { reliable status and trends determinations of species, genera, and systems; through analysis and } \\
\text { modeling, recommend valid and reliable inferences to identify species, genera, or functional } \\
\text { groups as indicators of ecosystems; enhance the multidisciplinary nature of models. }\end{array}$ \\
\hline $\begin{array}{l}\text { Data and information } \\
\text { management and reporting }\end{array}$ & $\begin{array}{l}\text { Ensure the availability of status and trends methodologies, analytic tools, data, information, } \\
\text { and products using the infrastructure of the NBII; identify needed priorities for data } \\
\text { and information to be made interoperable with those of other USGS Disciplines and } \\
\text { organizations; identify work needed to develop and implement a dynamic, online account of } \\
\text { the status and trends of the Nation's plants, animals, and ecosystems. }\end{array}$ \\
\hline
\end{tabular}




\section{List of Abbreviations}

\begin{tabular}{|c|c|}
\hline ARMI & Amphibian Research and Monitoring Initiative \\
\hline BBL & Bird Banding Laboratory \\
\hline $\mathrm{BBS}$ & Breeding Bird Survey \\
\hline BEST & Biomonitoring of Environmental Status and Trends \\
\hline BLM & Bureau of Land Management \\
\hline BRD & Biological Resources Discipline \\
\hline DOI & Department of the Interior \\
\hline EROS & Earth Resources Observation Systems \\
\hline FHM & Forest Health Monitoring \\
\hline FIA & Forest Inventory and Analysis \\
\hline FWS & U.S. Fish and Wildlife Service \\
\hline GAP & Gap Analysis Program \\
\hline GIO & Geographic Information Office \\
\hline IAFWA & International Association of Fish and Wildlife Agencies \\
\hline LTEM & Long-Term Ecological Monitoring \\
\hline LTER & Long Term Ecological Research Network \\
\hline LTRMP & Long Term Resource Monitoring Program \\
\hline NAAMP & North American Amphibian Monitoring Program \\
\hline NABCI & North American Bird Conservation Initiative \\
\hline NASQAN & National Stream Quality Accounting Network \\
\hline NAWQA & National Water-Quality Assessment Program \\
\hline NBII & National Biological Information Infrastructure \\
\hline NEON & National Ecological Observatory Network \\
\hline $\mathrm{NGO}$ & Non-governmental organization \\
\hline NLCD & National Land Cover Data \\
\hline NPS & National Park Service \\
\hline NRC & National Research Council \\
\hline NRCS & Natural Resources Conservation Service \\
\hline $\mathrm{OMB}$ & Office of Management and Budget \\
\hline PART & Program Assessment Rating Tool \\
\hline $\mathrm{S} \& \mathrm{~T}$ & Status and Trends \\
\hline USDA & U.S. Department of Agriculture \\
\hline USGS & U.S. Geological Survey \\
\hline
\end{tabular}




\section{References Cited}

Council on Environmental Quality (CEQ), 2002, Environmental indicators policy coordination: Memorandum to Department Secretaries from James L. Connaughton, Chairman of Council for Environmental Quality, December 31, 2002.

LaRoe, E.T., Farris, G.S., Puckett, C.E., Doran, P.D., and Mac, M.J., eds., 1995, Our living resources: A report to the Nation on the distribution, abundance, and health of U.S. plants, animals, and ecosystems: U.S. Department of the Interior, National Biological Service, Washington, D.C., 530 p. Available online at http://biology.usgs.gov/s+t/index. htm

Mac, M.J., Opler, P.A., Puckett Haecker, C.E., and Doran, P.D., 1998, Status and trends of the Nation's biological resources (Vol. 1 and 2): U.S. Department of the Interior, U.S. Geological Survey, Reston, Va., 964 p.

National Research Council (NRC), 1993, A biological survey for the Nation: Commission on the formation of the National Biological Survey, National Research Council, National Academy Press, Washington, D.C., 205 p.
U.S. Department of the Interior (DOI), 2003, Strategic plan FY 2003-2008: Available online at http://www.doi.gov/ppp/ strat_plan_fy2003_2008.pdf

U.S. Fish and Wildlife Service (FWS), 1999, Fulfilling the promise: The National Wildlife Refuge System: U.S. Department of the Interior, Washington, D.C., March 1999. Progress report available online at http://refuges.fws.gov/ habitats/promises.html

U.S. Geological Survey (USGS), 2002, U.S. Geological Survey Strategic Plan 2000-2005: Available online at http:// www.usgs.gov/stratplan/index.html

U.S. Geological Survey, Biological Resources Division (USGS), 1999, Status and Trends National Program Review: Available online at http://biology.usgs.gov/ status_trends/index.htm

U.S. House of Representatives, House Appropriations Committee, 1999, House Report 106-222: To accompany H.R. 2466: Department of the Interior and Related Agencies Appropriation Bill, 2000, 106th Cong., 1st session, p. 30.

Walters, C.J., 1986, Adaptive management of renewable resources: MacMillan Publishing Co., New York, N.Y., $374 \mathrm{p}$. 
ISBN 0-607-9เ2B8-9

|||||||||||||||||||||||||||

8 Printed on recycled paper

$9 l_{790607} \|_{962870}$ 